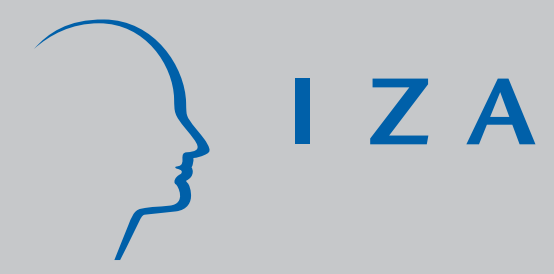

IZADP No. 1659

Is Early Learning Really More Productive? The Effect of School Starting Age on School and Labor Market Performance

Peter Fredriksson

Björn Öckert

J uly 2005 


\title{
Is Early Learning Really More Productive? The Effect of School Starting Age on School and Labor Market Performance
}

\author{
Peter Fredriksson \\ Uppsala University, IFAU \\ and IZA Bonn
}

Björn Öckert

IFAU, Uppsala

Discussion Paper No. 1659

July 2005

IZA

P.O. Box 7240

53072 Bonn

Germany

Phone: +49-228-3894-0

Fax: +49-228-3894-180

Email: iza@iza.org

Any opinions expressed here are those of the author(s) and not those of the institute. Research disseminated by IZA may include views on policy, but the institute itself takes no institutional policy positions.

The Institute for the Study of Labor (IZA) in Bonn is a local and virtual international research center and a place of communication between science, politics and business. IZA is an independent nonprofit company supported by Deutsche Post World Net. The center is associated with the University of Bonn and offers a stimulating research environment through its research networks, research support, and visitors and doctoral programs. IZA engages in (i) original and internationally competitive research in all fields of labor economics, (ii) development of policy concepts, and (iii) dissemination of research results and concepts to the interested public.

IZA Discussion Papers often represent preliminary work and are circulated to encourage discussion. Citation of such a paper should account for its provisional character. A revised version may be available directly from the author. 


\section{ABSTRACT \\ Is Early Learning Really More Productive? The Effect of School Starting Age on School and Labor Market Performance*}

In Sweden, children typically start compulsory school the year they turn seven. Hence, individuals born just before or just after the new year, have about the same date of birth but start school at different ages. We exploit this source of exogenous variation, to identify the effects of age at school entry on test scores, grades, educational attainment and labor market performance. Using a rich data set for the entire Swedish population born 1935-84, we find that children who start school at an older age do better in school and go on to have more education than their younger peers. Children from families with weaker educational tradition have more to win from starting school later. The long-run earnings effects are positive but small. However, since starting school later entails the opportunity cost of entering the labor market later, the net earnings effect over the entire life-cycle is negative. Exploiting withinschool variation in peer age composition, we find that the school starting age effect primarily is due to absolute maturity rather than to the relative age in the class.

JEL Classification: J24, 121

Keywords: child education, school starting age, regression-discontinuity design

Corresponding author:

Peter Fredriksson

Department of Economics

Uppsala University

P.O. Box 513

SE-751 20 Uppsala

Sweden

Email: peter.fredriksson@nek.uu.se

\footnotetext{
* We gratefully acknowledge the helpful comments from Olof Åslund and Roope Uusitalo. We also thank seminar participants at the IUI (Stockholm), SOFI (Stockholm), IFAU, FIEF (Stockholm), NTNU (Trondheim) the Universities of Copenhagen, Helsinki, Montreal, and Växjö, as well as participants in the EALE/SOLE 2005 conference, the CEPR conference on "Education and Inequality" (Bergen, August 2004), and the first EEEPE work shop (Amsterdam, November 2004) for valuable comments.

Öckert acknowledges the financial support from Jan Wallander's Foundation.
} 


\section{Introduction}

Evidence from small-scale early childhood education experiments suggests substantial gains in both scholastic achievement and later outcomes for the participating children (see Barnett, 1992; Currie, 2001 for two surveys). The relative magnitudes of the returns involved have led some authors to propose a reallocation of public spending from older to younger persons (for example Carneiro and Heckman, 2003). However, the existing preschool evidence reflects the net effects of multidimensional programs. These early interventions involve (i) more schooling, (ii) formal learning at a young age and (iii) targeted training towards disadvantaged children. Thus, the available preschool evidence is not very informative about the virtues of early learning for the average individual.

Basic human capital theory suggests that children should start formal learning as soon as possible. First, individuals who start school earlier also enter the labor market earlier, and can collect the returns from their human capital investments over a longer time horizon. Second, the opportunity cost for going to school is lower if they enter the labor market earlier, since labor market productivity can be assumed to increase with age. ${ }^{1}$ These arguments, however, implicitly assumes that early learning is at least as productive as later learning. There is, though, far from a consensus in the literature from different fields on when children are most receptive to schooling. Evidence from developmental behavioral genetics and molecular genetics suggests that some age ranges of child development (critical periods) are especially sensitive to the impact of specific types of experiences (Shonkoff et al., 2000). An extremist interpretation of these results is that many important abilities are fairly set by the age of six, and, hence, it is crucial that children start school early. Child developmentalists, on the other hand, have traditionally stressed the importance of school readiness: young children might not be mature enough to learn complicated things in a school environment.

There are also alternative explanations of why age at school start should matter. Children who start school early are also among the youngest in a class. Educationalists and developmental psychologists typically see achievement differences by month of birth within a class as relative age effects: children who are young when they start school have the disadvantage of being youngest in the class. On the other hand, economic theory predicts that older and more able peers can generate positive peer group effects: being surrounded by older children may generate benefits for younger children in school. Both these ex-

\footnotetext{
${ }^{1}$ In addition, they also have more work experience.
} 
planations suggest that changing the age at school start might not have that big an effect as long as the peer group age composition is kept intact. All in all, theory is inconclusive, and the age at which formal learning in a class room is most productive is an empirical question.

The empirical educational literature on the relation between age at school entry and (early) academic performance is extensive (see Stipek, 2002 for a survey). One group of studies compares the outcomes of children who have delayed entry with children who entered school when they were eligible. They typically find that children who have been held back perform less well than their same-age peers (Byrd et al., 1997; Graue and DiPerna, 2000; May et al., 1995). These results are probably misleading, however, since the suspicion of low academic performance is likely to be a source of delayed entry. Another group of studies compares the outcomes of children who entered school when they were eligible, but who differ in birth dates within the year. The evidence from this literature suggests that the youngest children in a class score slightly below their older peers, but that the differences tend to be small and transitory (Langer et al., 1984; Jones and Mandeville, 1990; Mayer and Knutson, 1999; Cahan and Cohen, 1989; Cahan and Davis, 1987). However, since low-performing children born just before the school cut-off date (youngest in class) probably are more likely to be held back than low-performing children born just after the cut-off date (oldest in class), these studies tend to underestimate the effect of school starting age. ${ }^{2}$ The common practice of retaining weaker children in many countries, might also explain the declining school starting age effects with grade level (Corman, 2003). Further, since age at test in compulsory school is an exact linear function of age at school start and time spent in school, these studies fail to separate the effect of age at school start from any general age effect.

Economists have shown less interest in the effects of age at school start on later performance. Angrist and Krueger (1992) use quarter of birth as an instrument for age at school entry to estimate the effect of school starting age on educational attainment. They find that children who start school at an older age have less schooling than children who start school when they are younger. However, since American compulsory schooling laws typically require students to remain in school until their sixteenth or seventeenth birthday, individuals who enter school at an older age reach the legal dropout age at an earlier point in their educational careers than students who enter school later. Thus, the

\footnotetext{
${ }^{2}$ For this reason Cahan and Cohen (1989) exclude the months preceding and following the school cut-off date.
} 
possible effects of school starting age are contaminated by the effects of school leaving age legislations. For the same reason, estimates of quarter of birth on education and earnings using American data are hard to interpret as the (reduced form) effects of school starting age (e.g. Angrist and Krueger, 1991; Bound et al., 1995; Mayer and Knutson, 1999). ${ }^{3}$

In this paper we estimate the effect of school starting age on performance in school and on the labor market. We use rich administrative data for the entire Swedish population born 1935-84, containing information on compulsory school grades, educational attainment, employment and earnings. The endogeniety of school starting age is accounted for by using expected age at school entry defined as the age when the child is supposed to start school according to her month of birth and the school cut-off date - as an instrument for actual school starting age. To break the exact linear dependence between age at school start, age at test and time spent in school, we estimate the effects of school starting age not only on compulsory school outcomes but also later in life. Individuals born just before or just after the school cut-off date - and who have completed compulsory school - then have about the same age and the same amount of compulsory schooling, but differ in their expected school starting age by almost a year. We also attempt to disentangle the effects of the absolute school starting age from the effects of the relative age in the class, by exploiting within-school variation in the peer group age composition.

The results show that children who start school when they are older do better in all subjects in school. In particular, children with weaker educational backgrounds have more to win from starting school later. Individuals who are older when they start school also go on to have more schooling and are more likely to graduate from college than other individuals. The earnings effects of age at school start are negative for the youngest birth cohorts - since children who start school later also enter the labor market later - but the long run effects are positive (although small). The net effect over the entire life-cycle is negative.

The outline of this paper is as follows. The next section provides some basic facts about child care and schooling in Sweden. Section 3 describes the data and gives some descriptive statistics. In section 4 a graphical analysis is provided. This is followed by empirical considerations in section 5 and the results in section 6. Section 7 concludes.

\footnotetext{
${ }^{3}$ Recently, a number of economists have shown interest in the effect of age at school start and related questions; see, e.g., Plug (2001), Strøm (2003), Cascio and Lewis (2004), Del Mondo and Galindo-Rueda (2004), Leuven et al. (2004), Bedard and Dhuey (2005), Datar (2005), and Fertig and Kluve (2005).
} 


\section{Child care and schooling in Sweden}

Today, Sweden offers nine years of tuition-free compulsory education, generally starting at age seven. Compulsory schooling provides comprehensive education, so everyone follows basically the same curriculum; the curriculum is determined by the central government.

Prior to entering school, all children participate in a Kindergarten-type of preschool class starting at age six. However, there is also the possibility for children to start regular schooling at age six. Most children below the age of six are enrolled in child care. Child care is not free of charge, but is heavily subsidized.

Upper-secondary school is voluntary and offers several programs, ranging from vocational training to programs that prepare for further studies at the university level. Today, practically all eligible students (meaning that they have passed all courses at the compulsory level) go on to upper-secondary school.

University education is tuition free and anyone who has completed three years of upper secondary education is generally eligible for university studies. The total number of slots is determined by a central agency, so there is selection into popular programs and universities. All university students are eligible for student grants and subsidized student loans, provided that their income does not exceed an income ceiling. The university enrollment rate appears to be relatively high in Sweden: 42 percent of the population aged 20-24 participate in education; the corresponding number for all OECD countries is 37 percent (OECD, 2003).

On top of all this, there is also an extensive adult education program. The typical adult education program consists of studies at the upper secondary level. Adult education is subsidized to a greater extent than university studies.

For obvious reasons, we are mostly interested in the lower levels of schooling in this paper. In the next subsection, therefore, we provide a description of the evolution of compulsory education with particular emphasis on the school starting age and child care.

\subsection{The evolution of child care and schooling in Sweden}

An important goal of Swedish education policy has been to equalize opportunity. At least this is the impression you get from reading the policy documents. When it comes to the concrete implementation of policies, the objective has been to equalize educational outcomes per se and to reduce the importance of family background in educational attainment. Indeed, the latter type of policies has 
also been motivated from an efficiency point of view.

Figure 1 presents a summary picture of educational attainment for successive cohorts born between 1935 and 1975. The solid line depicts mean years of schooling, while the dashed lines shows the mean \pm one standard deviation of the schooling distribution. As expected, mean years of schooling increases for successive birth cohorts. What is perhaps most striking in this figure is the substantial reduction in the spread of the schooling distribution. In fact, a closer examination of the data reveals that the evolution of the mean, as well as the standard deviation, is mostly driven by what goes on in the lower tail of the schooling distribution. It thus seems that educational policies have been primarily designed to lift the lower tail of the distribution during the 40 years spanned by these birth cohorts.

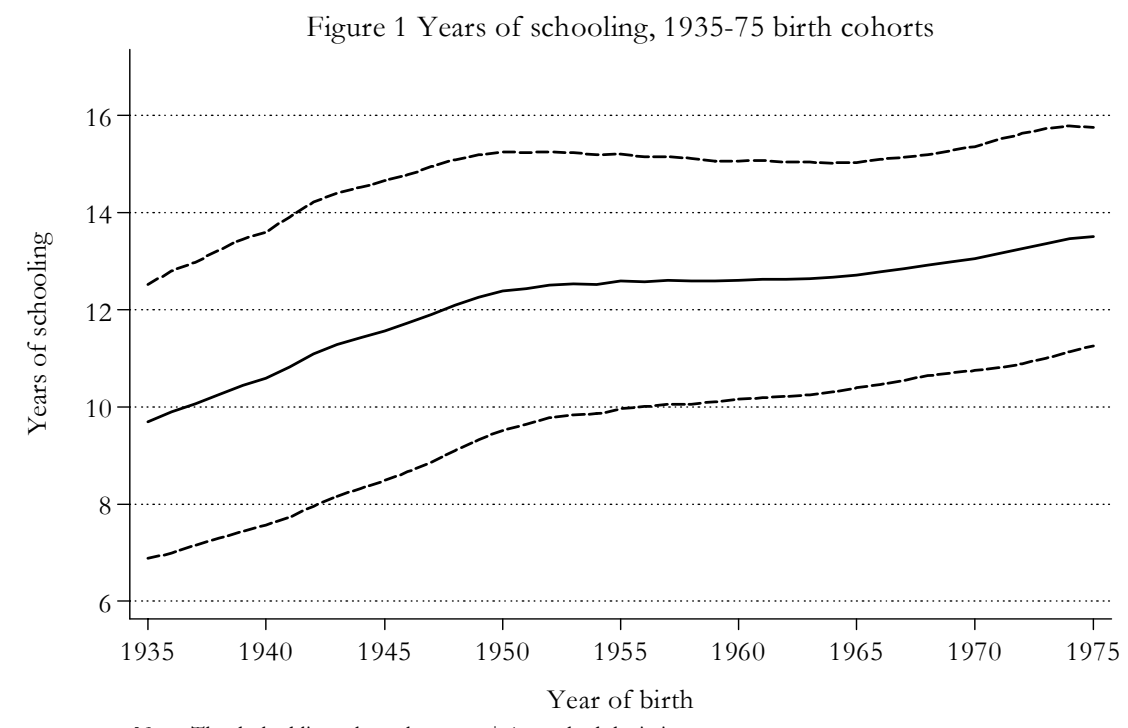

Note: The dashed lines show the mean \pm 1 standard deviation.

Table 1 provides more details on the development of compulsory education and the school starting age. ${ }^{4}$ Compulsory schools were formally introduced as early as 1842 . To start off with, the school starting age was varying between 5 and 9 years-of-age and the minimum school requirement was 4 years of education. However, compulsory education was far from "compulsory". It was not until the late 1920s, that the vast majority (92 percent) fulfilled the minimum school requirement of six years.

\footnotetext{
${ }^{4}$ We base this presentation on Gunnarsson et al. (1999).
} 


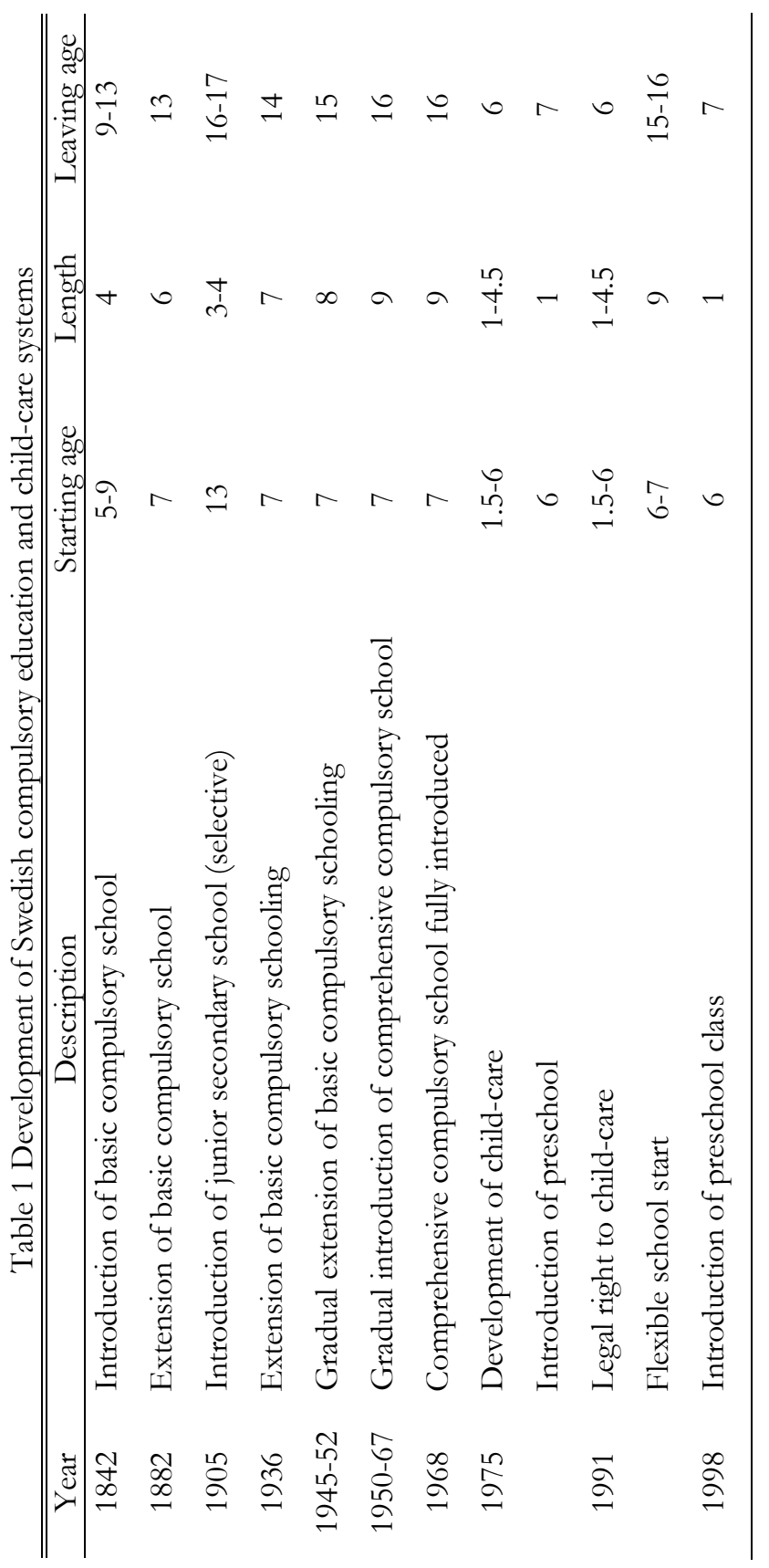


The school system during the first half of the 1900s was rather selective. Moreover, compulsory schools were run locally and local authorities determined the curriculum. However, this was changed by a parliamentary decision in 1950. A comprehensive school, with a nationally determined curriculum, was introduced gradually across the country. The comprehensive school was fully implemented all across the country in 1968.

The later reforms covered by Table 1 have concerned child care, pre-school, and the school starting age. By international standards, public day-care has a long history in Sweden: public allowances for day-care were introduced already in 1944. The amounts were, however, small and day-care was primarily organized privately. In the 1970s, the public took a greater interest in day-care. In 1976, the Swedish parliament decided on a massive increase in the number of day-care slots. Despite the increase in the number of slots, the majority of parents still had to organize day-care privately. In the mid 1980s, there was yet another build-up of public day-care and in 1991 all children of working and studying parents were given the legal right to a child care slot.

Figure 2 presents the share of 5 year-olds enrolled in child-care for the cohorts born 1970-1996. The massive expansion of child-care is readily visible in the data. The enrollment share is steadily increasing over time and roughly 80 percent of those born in 1996 is participating in child care.

Figure 2 Share of 5 year-olds enrolled in child care, 1970-96 birth cohorts

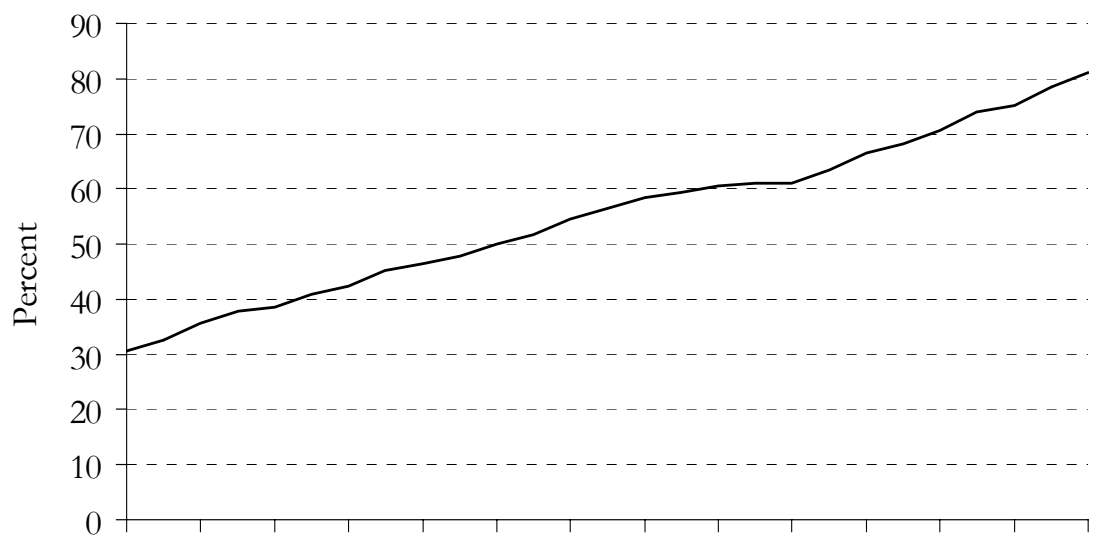

19701972197419761978198019821984198619881990199219941996

Year of birth

Along with the initial build-up of child care, preschools were introduced in 
the mid 1970s. The preschools were given a greater class room training component, when the so called preschool classes were introduced in 1998. Finally, a flexible school start was introduced in 1991. From then on parents can enroll their children in compulsory school at age 6 rather than at age 7 ; roughly three percent of the cohorts born in 1991 and 1992 have used this possibility.

Given all these changes to child care, preschool, and the school starting age it is legitimate to ask when formal schooling really starts in Sweden. If one would argue that child care and pre-schools constitute formal schooling, then the expected school starting age has declined from 4.9 years for the cohort born in 1975 to 2.8 years for the cohort born in $1996 .{ }^{5}$ Let us make two observations in this regard. First, our analyses of the long-run effects focus mostly on cohorts born prior to 1975. For these cohorts, child care is only a minor issue. Second, the regression-discontinuity design that we are utilizing (section 5 details our empirical approach) only applies to the school year. Children eligible for child care, at least in principle, have the right to a slot when they turn one whenever this occurs during the year.

Nevertheless, the contents of "treatment" (starting school at a younger age) and the "alternative" (starting at an older age) appear to be changing over time. Changes in pedagogical techniques and the selectiveness of the entire school system influence the treatment. Likewise, the alternative is changing for successive birth cohorts. The alternative usually meant staying at home with one parent for the cohorts born in the 1940s, 1950s, and most of the 1960s. But for cohorts born in the 1970s it has increasingly become attending child care. To deal with these concerns we will report separate estimates for successive birth cohorts.

\section{$3 \quad$ Data and descriptive statistics}

The data have mainly been collected from administrative records but also from some surveys. The administrative data originates from Statistics Sweden and cover the entire population born in Sweden 1935-84. All in all, there are roughly 4.8 million observations. ${ }^{6}$ All individuals have been matched with different reg-

\footnotetext{
${ }^{5}$ Indeed this seems to be the view taken by policy makers in Sweden. What we are referring to as child-care, is really called preschool in the policy documents. Moreover, Swedish child care is considered early childhood education in international statistics.

${ }^{6}$ We exclude all 900,000 immigrants (this may include native-born who have spent at least a year abroad), since they lack reliable information on date of birth, school starting age and years of schooling. Further, individuals who have deceased or emigrated by the year of 2000 are not covered by the data.
} 
isters using their unique identity number. Information on year and month of birth originates from birth records, and should in principle not suffer from measurement errors. Individuals born 1941-1982 have been linked to their biological parents, and information on parental highest education have been obtained from the censuses. The coverage of the parental information increases with year of birth and is 80 per cent or higher for individuals born after 1960 .

The school starting age is unfortunately not reported in Swedish administrative records. We will therefore use different data sources to construct such a measure. For individuals born 1972-84 there is information on the year of compulsory school completion (in ninth grade). Since grade retention or advancement rarely is practiced in Swedish schools, potential mis-classification is a very minor issue. ${ }^{7}$ Therefore, we calculate the school starting age for these cohorts as:

$$
A_{i}^{S}=\left(Y O C_{i}-Y O B_{i}\right)-9+\left(\frac{8-M O B_{i}}{12}\right)
$$

where $A_{i}^{S}$ is school starting age, $Y O C_{i}$ is the year of compulsory school completion, $Y O B_{i}$ is the year of birth (9 is the number of years in compulsory school), and $M O B_{i}$ is the month of birth (ranging from 1 to 12, and 8 reflects the fact that schools start in August). Thus, $A_{i}^{S}$ is measured in yearly units but varies by month of birth.

To obtain a measure of school starting age for earlier cohorts we make use of the first and second surveys of the Individual Statistics (IS) project of the Institute for Education and Educational Research at the University of Göteborg. These two surveys cover all individuals born in Sweden on the 5th, 15th or 25th of any month in 1948 or 1953, respectively. These data include intelligence test scores and achievement test scores in sixth grade. For the 1948 cohort there is information on the year the pupils entered grade one and in the 1953 cohort there is data on the grade the individuals attended in the 1965/66 school year. We use this information to calculate age at school entry (using equation (1) with fewer years of compulsory schooling). The school starting age in the IS samples is then regressed on month of birth to predict the school starting age for the 1935-71 cohorts in the administrative data.

\footnotetext{
${ }^{7}$ Corman (2003) and Eide and Sholwater (2001) show that grade retention and advancement is strongly related to season of birth in the U.S. In Sweden, however, children rarely repeat or skip grades. Data for the 1960s suggest that half of those finishing late (only $3.6 \%$ of the population) were retended during compulsory school. As we show in Table 3, the first-stage coefficient in the regression of the actual school staring age on the expected school starting is 0.91 . The data for the $1960 \mathrm{~s}$, then suggest that absent misclassification this reduced form coefficient would be in the order of 0.96 . Whether we construct the "structural" estimate using 0.91 or 0.96 is of no practical importance.
} 
Final grades from compulsory school is collected by Statistics Sweden for the 1988-2000 period. The normal graduation age is 16 years, so this information is in principle available for the 1972-1984 cohorts. However, due to delayed entry for some individuals, we have complete compulsory school grades for the 1975-83 cohorts only. ${ }^{8}$ The register contains information on grades for all subjects. In most of the period studied, the grading system was relative. The grades ranged from 1 to 5 (with 5 being the highest grade) and were set such that the national average was 3 (with a unit standard deviation). With the implementation of a new curriculum - which affected those graduating in 1998 - the relative grading system was replaced with an absolute (or goal-oriented) system. There are four levels of grades in the new system: fail, pass, pass with distinction and pass with special distinction. To make these different grading systems comparable, we attach a percentile rank to each grade for all subjects. ${ }^{9}$

To guide teachers in their grading, national achievement test have been undertaken in both the old and the new grading system. These results are, however, only advisory, and teachers might deviate from them. As long as teachers do not systematically overcompensate or punish some groups, this should not be a problem. To assess the information value contained in the grades we use data from the IS surveys, which, as already noted, contain information on, inter alia, achievement test scores.

Statistics Sweden collects information on the highest level of education completed for all individuals. We convert the highest educational level attained into years of education using the Swedish Level of Living Survey (SLLS) conducted in 2000. The SLLS contains information on educational attainment and labor market success for a representative sample of individuals between 18 and 75 years, in all about 5,000 observations. What is convenient for our purposes is that it includes both register information on highest level of education and survey information on time spent in school. We predict years of education for the entire population using the estimates from a regression of years of education in the SLLS on the educational levels according to the register information. To allow years of schooling associated with each level of education to vary smoothly across cohorts, we estimate separate regressions for each birth cohort ( \pm five cohorts).

\footnotetext{
${ }^{8}$ To get complete data for a full birth cohort, compulsory school grades for individuals who have an early (delayed) school start or who have been advanced (retained), are collected from the preceeding (subsequent) school years.

${ }^{9}$ Hence, we have ranked the grades in the old and the new system separately. In the empirical analysis, we let year of birth fixed effects capture any cohort trends in the grades.
} 


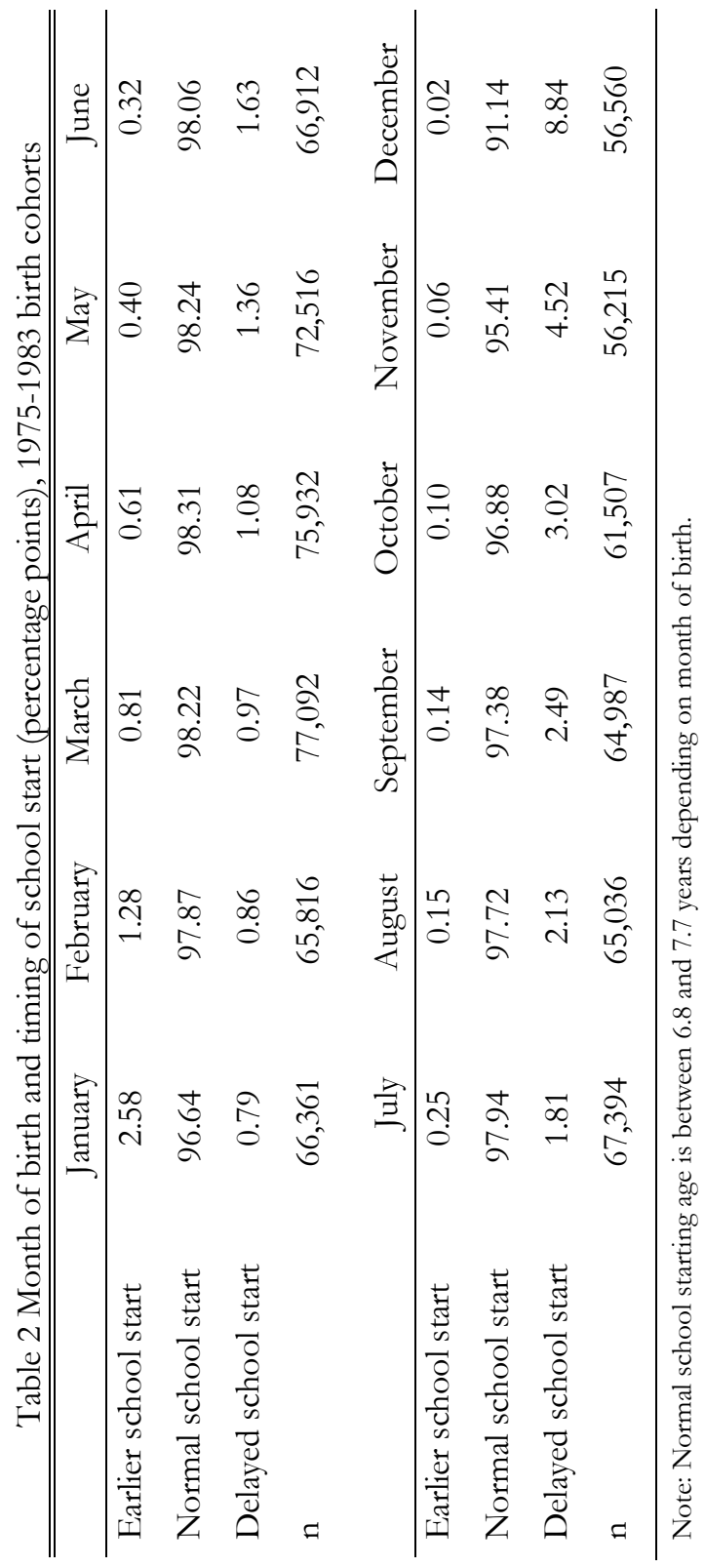


Our earnings measure is based on register information. It is measured as of 2000 and defined as the sum of annual gross wage earnings and compensation during temporary work absence (basically due to illness or parental leave) in SEK. ${ }^{10}$

The average school starting age in our sample is 7.2 years. ${ }^{11}$ Children typically start school between the ages 6.8 and 7.7 , but some children start school already at the age of five and others not until they turn ten years old. Table 2 shows the share of children with an early, normal or delayed school start by month of birth for the 1975-83 birth cohorts. Even though parents and school administrators can affect the timing of the children's school start to some extent, roughly 97 per cent of all children start school the year they turn seven. The probability of a delayed or an early school start varies with month of birth. About 2.6 per cent of the children born in January start school one year too early. The probability of an early school start falls monotonically for later months of birth, and is negligible for children born in December. The opposite pattern is found for delayed school start, where as much as 8.8 per cent of children born in December begin school one year late. The share of children with a delayed school start falls monotonically for children born earlier in the year.

\section{Graphical analysis}

In Sweden, only three per cent of the children start school earlier or later than the year when they turn seven. Such a small share might seem negligible, but might still be enough to produce a misleading correlation between school starting age and later performance. Figure 3 shows the relation between age at school start and the ninth grade grade point average (GPA) for the 1975-83 birth cohorts. The performance in compulsory school by school starting age exhibit a stepwise negative relationship. Taken at face value, this would suggest that children who start school earlier do better than children who start school later. Note, however, that the downward trend, is driven by sharp "falls" in the performance just at the minimum and maximum normal school starting age (6.8 and 7.7 years, respectively). Within each segment of early, normal and delayed school starters, there seems to be no or - in particular for the group of normal school starters - a positive relation between the age at school entry and ninth grade GPA. This highly irregular relation between age at school start

\footnotetext{
${ }^{10}$ The information comes from the tax assessment as well as the employers' and authorities' statements of income and allowances.

${ }^{11}$ Table A1 in Appendix reports descriptive statistics for the 1935-84 birth cohorts.
} 
and compulsory school performance is, thus, likely to be due to the non-random selection of children with early or delayed school start and cannot be given a causal interpretation.

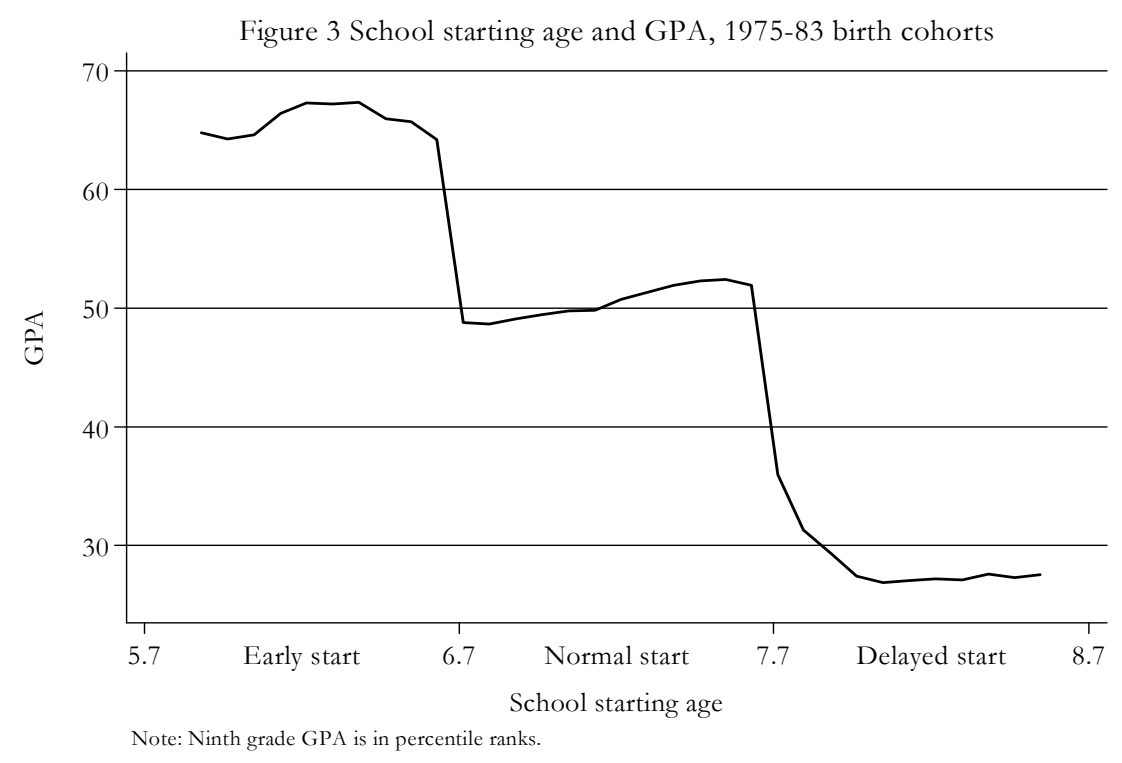

The empirical strategy in this paper is to exploit the exogenous variation in school starting age caused by the children's month of birth and the school cut-off date. The school starting age legislations induces the following expected school starting age function:

$$
f_{i}^{A^{S}}=7.7-\frac{M O B_{i}-1}{12}
$$

where $f_{i}^{A^{S}}$ is the age child $i$ is expected to start school. Children born in January $\left(M O B_{i}=1\right)$ typically start school at 7.7 years. For individuals born later in the year, the expected school starting age function falls monotonically to 6.8 years for children born in December. The function then makes a sharp jump back to 7.7 years at January 1st, generating a saw-teeth shaped pattern for age at school entry by month of birth.

Earlier studies of the effect of school starting age typically focus on the performance in compulsory school. Usually, the data is collected for all pupils born a specific year who are in the same grade. Although we use data on early academic achievement for all individuals in a birth cohort (and not only those who have a normal school start), our study of early outcomes is not an exception. 
There is, however, an exact linear dependence between age, age at school start and time spent in school for children still enrolled in compulsory school:

$$
A_{i t}=A_{i}^{S}+S_{i t}^{C},
$$

where $A_{i t}$ is age at $t$ (the time of data collection), $A_{i}^{S}$ is school starting age and $S_{i t}^{C}$ is compulsory schooling at $t$. Children who start school when they are somewhat older, are, thus, somewhat older also when they do the test (or get the grades) in a given grade. Again, using the school starting age legislations, expressions (2) and (3) can be used to derive an expected age function at time $t$ for children in a given grade:

$$
f_{i t}^{A}=f_{i}^{A^{S}}+s_{t}^{C}=7.7-\frac{M O B_{i}-1}{12}+s_{t}^{C},
$$

where $f_{i t}^{A}$ is the expected age function and $s_{t}^{C}$ is a given grade in compulsory school. The only difference between the expected school starting age and the expected age functions is the constant grade level. It is, thus, not possible to freely vary expected age and expected age at school entry for children enrolled in the same grade of compulsory school. So differences in compulsory school performance by month of birth may reflect not only school starting age effects but also age effects.

Figure 4 illustrates the expected age and expected school starting age profiles induced by the school starting age legislations for different data collection strategies. When the data are collected for all individuals in the same grade of compulsory school, the saw-teeth shaped pattern for the expected school starting age function is transmitted to the expected age function. This is illustrated in Panel A of Figure 4. Children born just after the school cut-off date start school one year later than children born just before the cut-off. Since the data is collected in the same grade, the outcomes of children born in January are collected one year later than for children born in December. Consequently, children born just after the break-point are older when they start school and when they do the test (or get the grade) than children born just before the break-point. 
Figure 4 Age and school starting age profiles induced by the school starting age legislation and different data collection strategies

Panel A Repeated cross-sectional data collected in the same grade of compulsory school at different points of time.

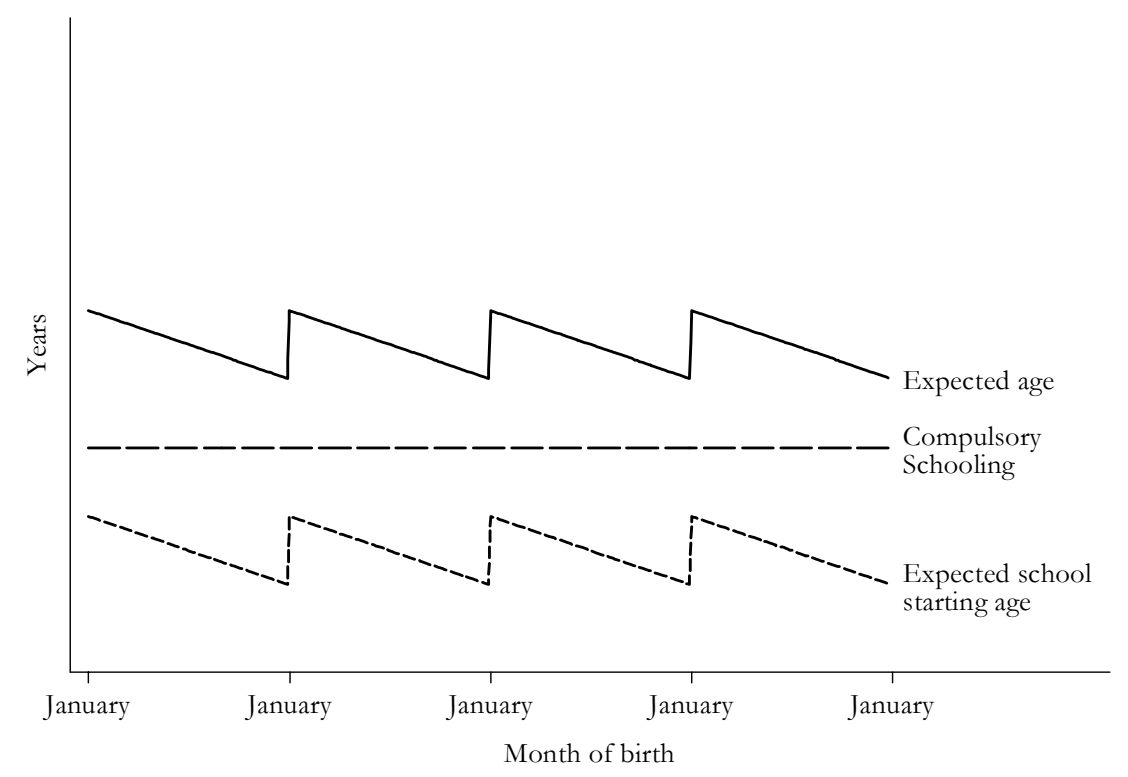

Panel B Cross-sectional data collected after compulsory school at the same point of time.

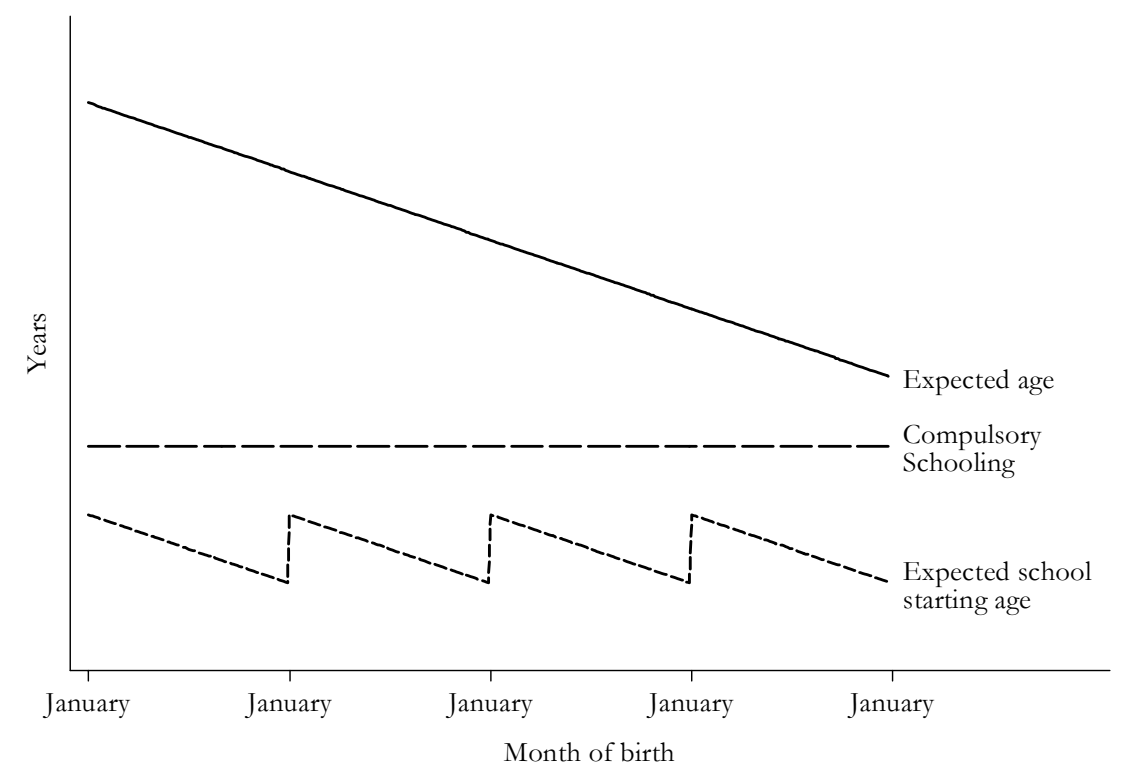

Note: The figure shows prototypical age and school starting age profiles induced by the school starting age legislations and different data collection strategies. Panel A shows the profiles for repeated cross-sectional data collected for all individuals in a given grade of compulsory school at different points of time. Panel B shows the profiles for cross-sectional data collected for all individuals after compulsory school at the same point of time, respectively. 
To break the exact linear dependence between age, age at school entry and time spent in compulsory school, we use data collected at the same point in time for individuals who have completed their compulsory schooling. The expected age function then corresponds to the individuals' actual age, and is not affected by the age at school entry. This is illustrated in Panel B of Figure 4. In particular, children who are born just before or just after January 1st have approximately the same age at the time of observation, the same amount of compulsory schooling but start school at different ages. For this population, the only difference is their expected age at school entry. The timing of the data collection is, thus, crucial for separately identifying the effect of the school starting age; this point is also made by Hansen et al. (2004).

Figure 5a shows the "first-stage" relation between expected and actual age at school entry by year and month of birth. Clearly, the actual age at school start follows closely the age when children are expeted to start school. Children born early in the year on average start school at the age of 7.7 years. The age at school entry then falls monotonically by month of birth to about 6.8 years for children born in December. It then jumps back to an average school starting age of 7.7 years for children born the following January, generating a saw-teeth pattern between age at school entry and date of birth. This suggests that children born on different sides of the new year typically start school with an age difference of almost a year.

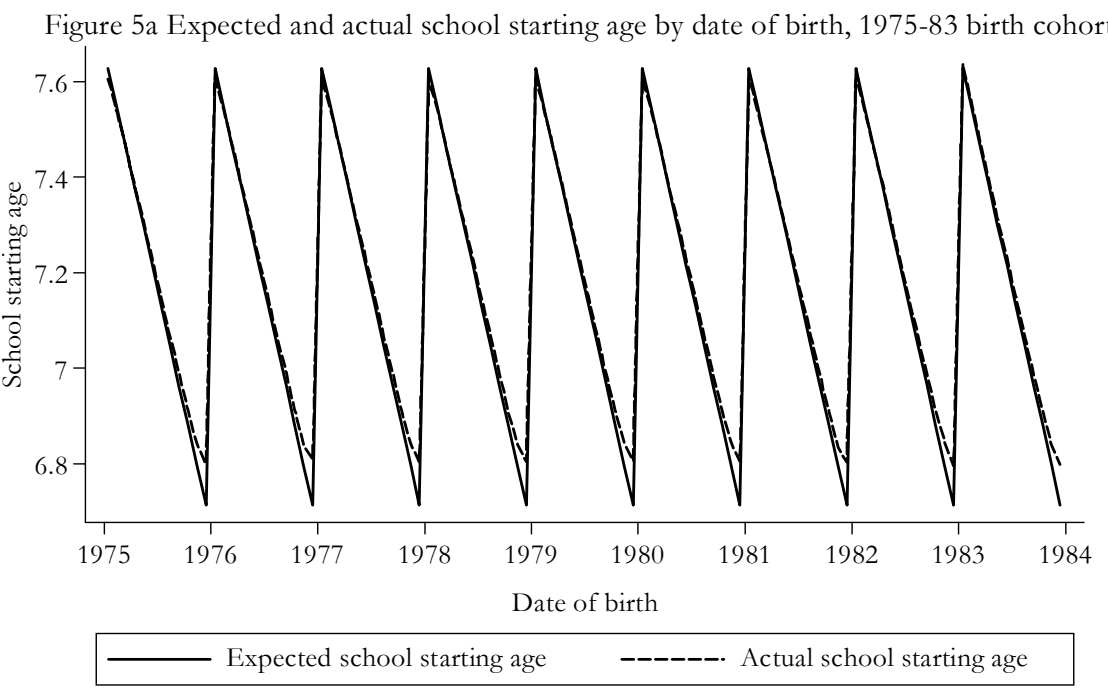

Note: Expected school starting age is the age when an individual is expected to start school according to month of birth and the school cut-off date. 
In addition to exhibiting a strong association with the actual school starting age, the expected school starting age is also correlated with the average ninth grade GPA. This is shown in Figure 5b. The average GPA follows closely the saw-teeth pattern of the average school starting age, with sharp jumps in student achievement just around the school cut-off date. Hence, children born in the beginning of the year on average perform better in school than children born later. The difference in average GPA between January and December births is about 5 percentile points. Even though it is, in principle, possible for parents to plan the date of birth for their children, it is hard to imagine that this can be accomplished with greater accuracy. Hence, it is reasonable to believe that the variation in age at school entry driven by month of birth and the school cut-off date is exogenous, and that the better performance of children born early in the year is caused by the differences in the school starting age.

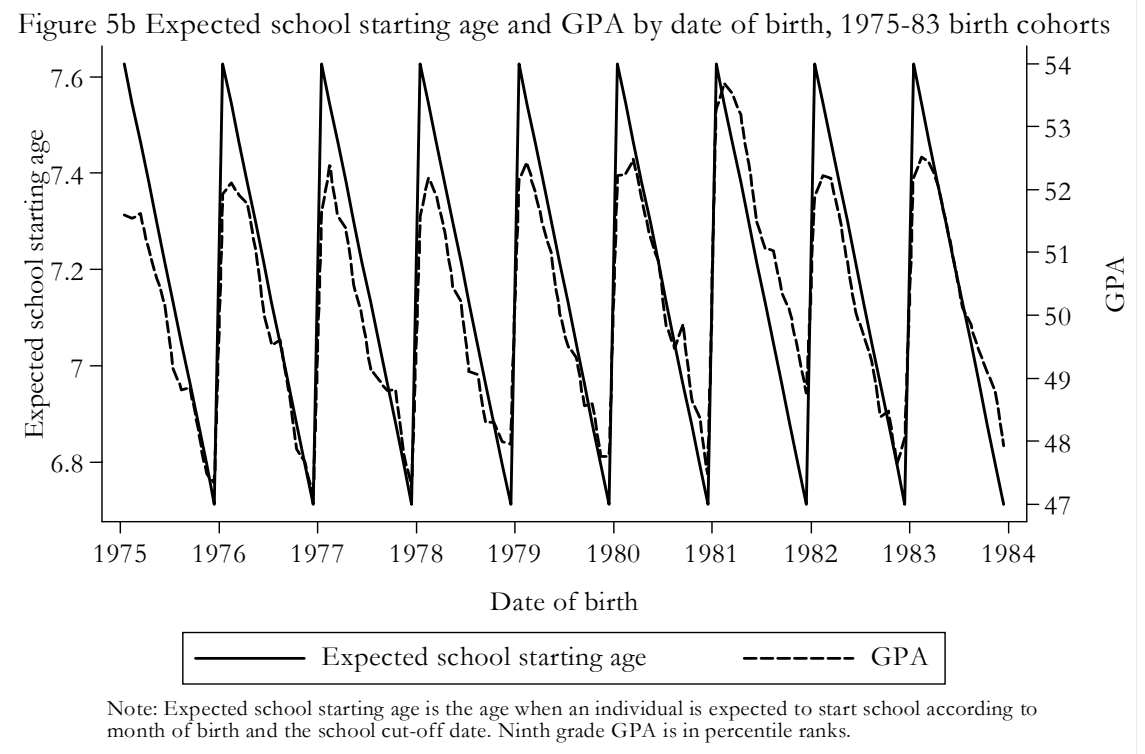

The observed relation between month of birth and ninth grade GPA might reflect differences in school starting age and/or differences in age. To separate the effect of age at school entry from any general age effect - and to study the long-run effects of school starting age - we next present data on schooling and earnings by month of birth. As noted in Figure 1, there is a strong positive trend in educational attainment for cohorts born 1935-75. Also, we expect the standard concave age-earnings profiles to produce a negative trend in earnings by year of birth. To abstract from any general time trends, we detrend the data 
on schooling and earnings by month of birth by subtracting off the average for each birth cohort.

Figures 6a-6d depict the relationship between average years of education in 2000 and season of birth for each ten-year birth cohort. The figures clearly show that season of birth is related to educational attainment. Contrary to what Angrist and Krueger (1991) find, however, individuals born in January have more schooling on average than those born in December. Thus the sharp discontinuity in the expected school starting age is translated into big jump in educational attainment around the break-point. This pattern is strongest for those born in the 1940s and the regularity holds for all birth cohorts born before 1975. For those born in the late 1970, the relationship is reversed. This is because these individuals have not yet finished their educational careers. Individuals born in the beginning of the year start school one year later, and, thus, are more likely to still be enrolled in school or college than individuals born at the end of the year. The schooling figures indicate that the observed relation between season of birth and ninth grade GPA cannot solely be explained by age differences. Individuals born at the end of the year or in the beginning of the next have about the same age but start school at different ages. There, thus, seems to be a long-lasting positive effect of age at school start on educational attainment.

Figure 6a Expected school starting age and years of schooling by date of birth, 1940-49 birth cohorts

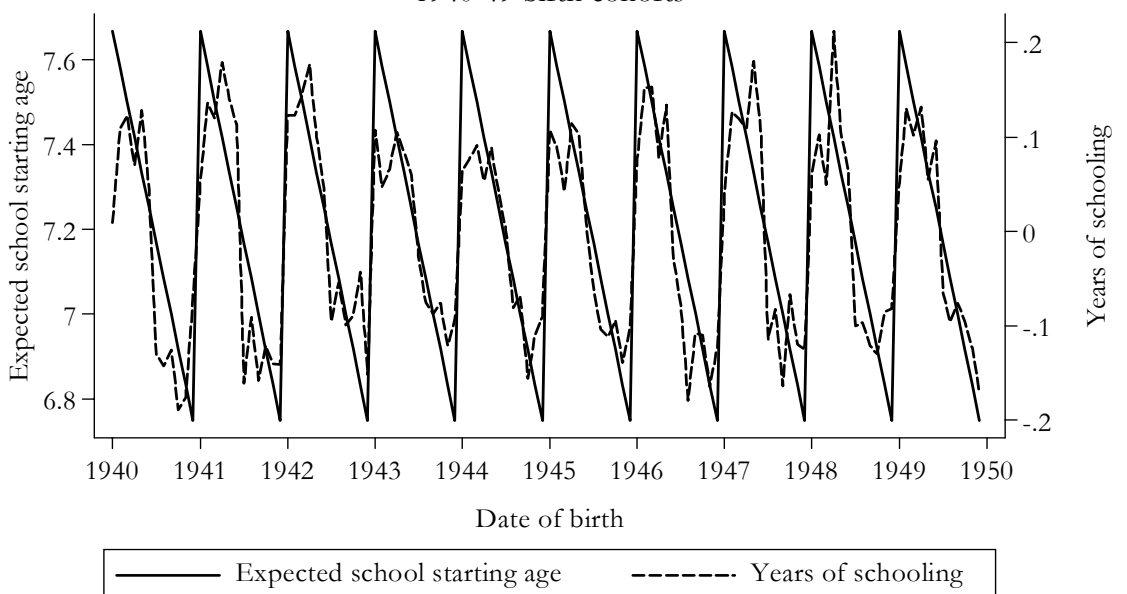

Note: Expected school starting age is the age when an individual is expected to start school according to month of birth and the school cut-off date. The years of schooling variable has been detrended by subtracting 
Figure 6b Expected school starting age and years of schooling by date of birth, 1950-59 birth cohorts

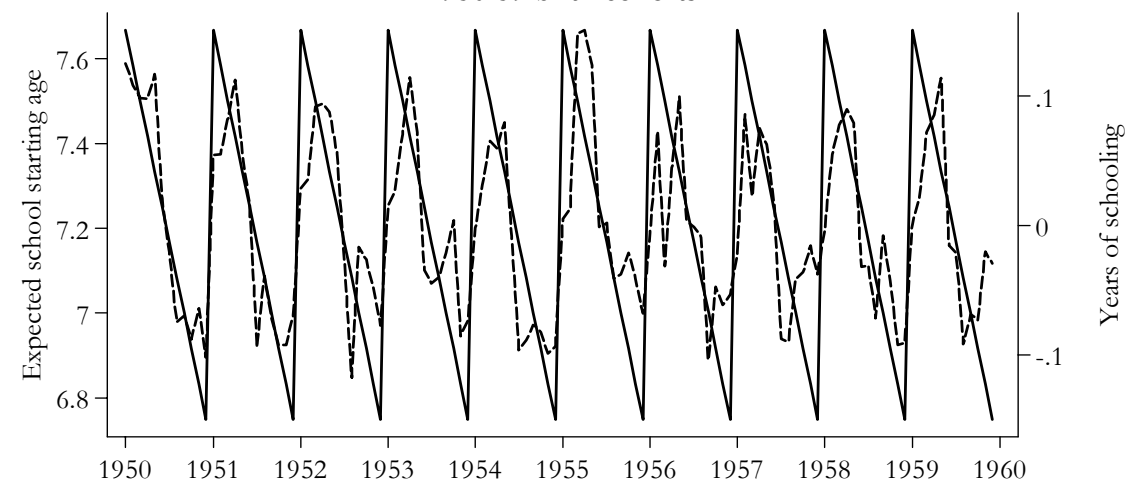

Date of birth

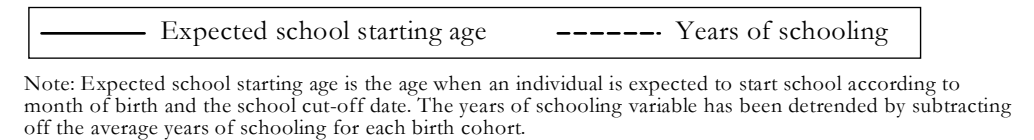

Figure 6c Expected school starting age and years of schooling by date of birth,
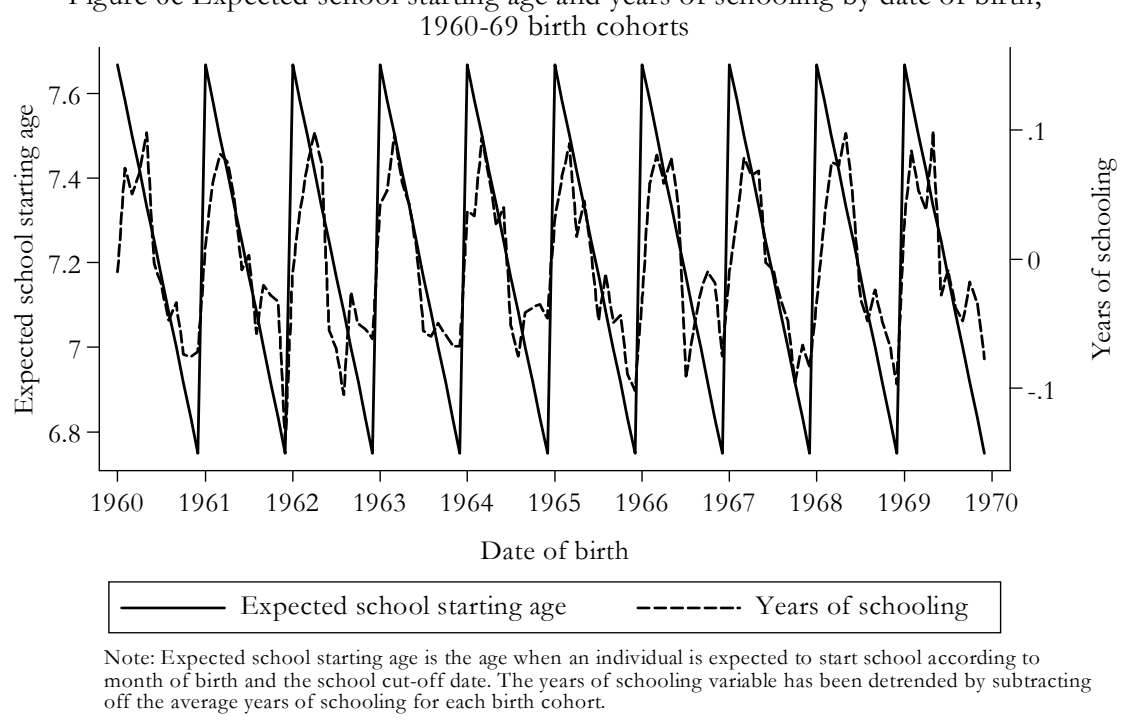
Figure 6d Expected school starting age and years of schooling by date of birth, 1970-79 birth cohorts
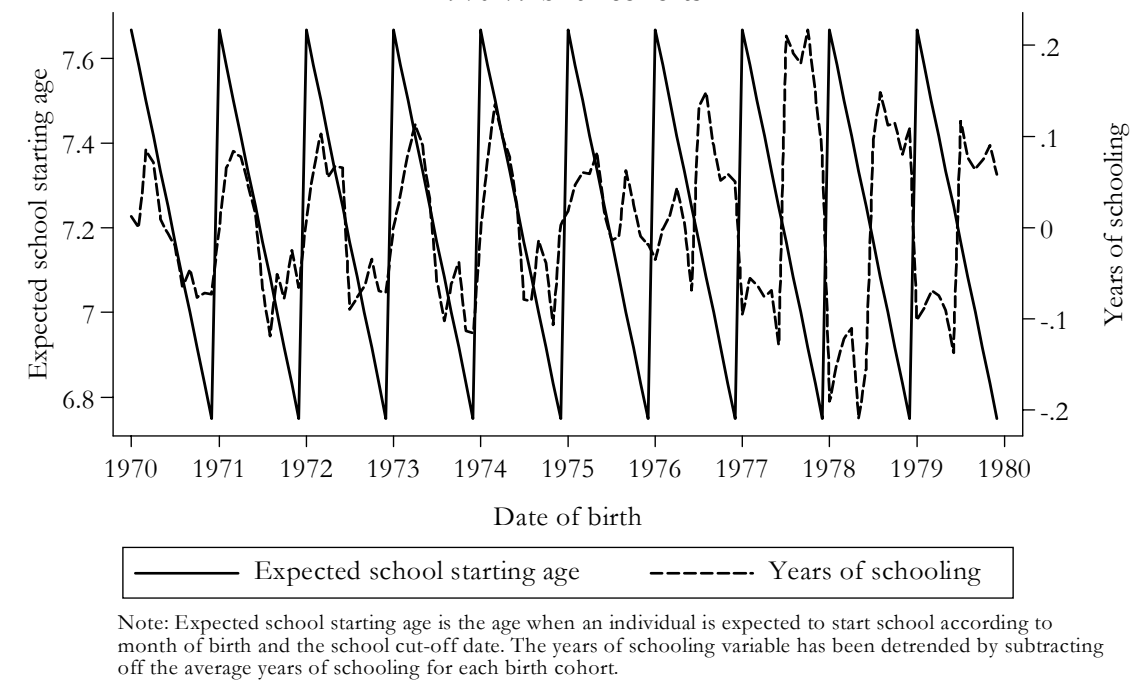

Figures 7a-7d show the expected school starting age and detrended median log earnings in 2000 for each ten-year birth cohort between 1940 and $1980 .^{12}$ The pattern is considerably more erratic for earnings than for education. However, the sharp increase for those born in January relative to those born in December is still visible in the data for those born in the 1940s. In particular, the effect is substantial for individuals born in the early 1940s (note the scale differences in Figures 7a-7d), i.e. for those who are approaching their retirement age (typically at their 65 birthday). This suggests that individuals who are more likely to start school one year earlier are also more likely to leave the labor market earlier. Hence, the argument that children should enrol in school earlier, so that they can collect the returns from their human capital investments for a longer time, might not be so obvious. That starting school later entail a substantial opportunity cost is shown by the data for those born in the second half of the 1970s. The pattern between date of birth and log earnings is reversed for these individuals. Thus those who begin school at an older age enter the labor market later. Also, there is a higher probability for individuals born in the beginning of the year to still be enrolled in school or college. Finally, they typically have one year of labor market experience less.

\footnotetext{
${ }^{12}$ Notice that individuals with no earnings are included in the sample and assigned the lowest value of log earnings.
} 
Figure $7 \mathrm{a}$ Expected school starting age and log earnings by date of birth, 1940-49 birth cohorts

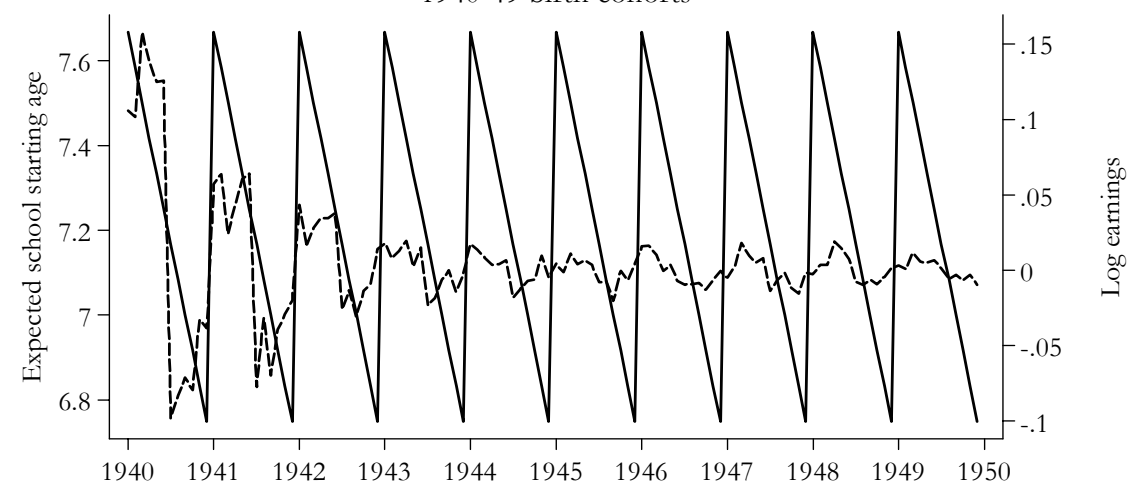

Date of birth

Expected school starting age
$\begin{aligned} & \text { Note: Expected school starting age is the age when an individual is expected to start school according to } \\ & \text { month of birth and the school cut-off date. The median log earnings has been detrended by subtracting } \\ & \text { off the median log earnings for each birth cohort. }\end{aligned}$

Figure 7b Expected school starting age and log earnings by date of birth,

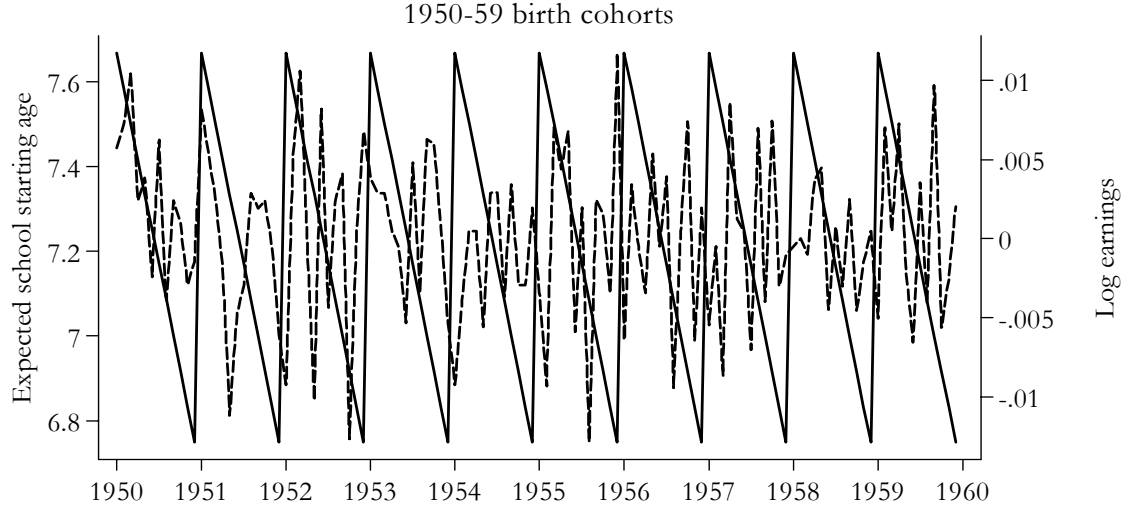

Date of birth

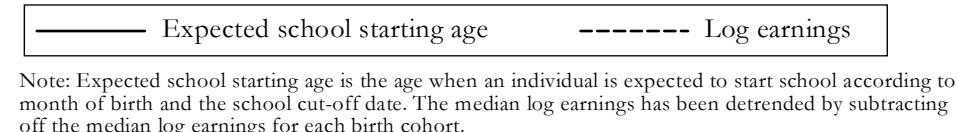


Figure 7c Expected school starting age and log earnings by date of birth, 1960-69 birth cohorts

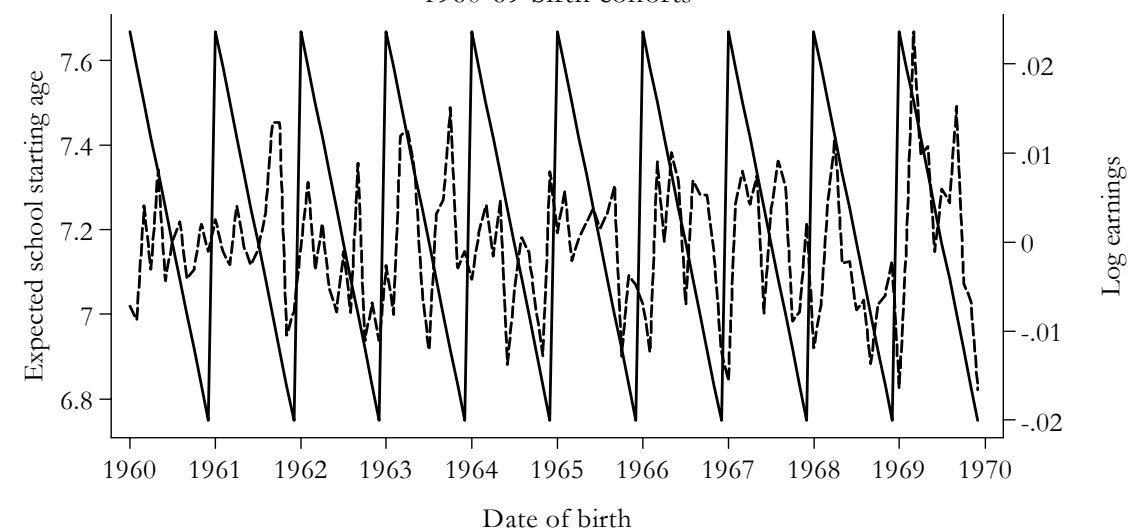

Expected school starting age
Note: Expected school starting age is the age when an individual is expected to start school according to
month of birth and the school cut-off date. The median log earnings has been detrended by subtracting
off the median log earnings for each birth cohort.

Figure $7 \mathrm{~d}$ Expected school starting age and log earnings by date of birth,

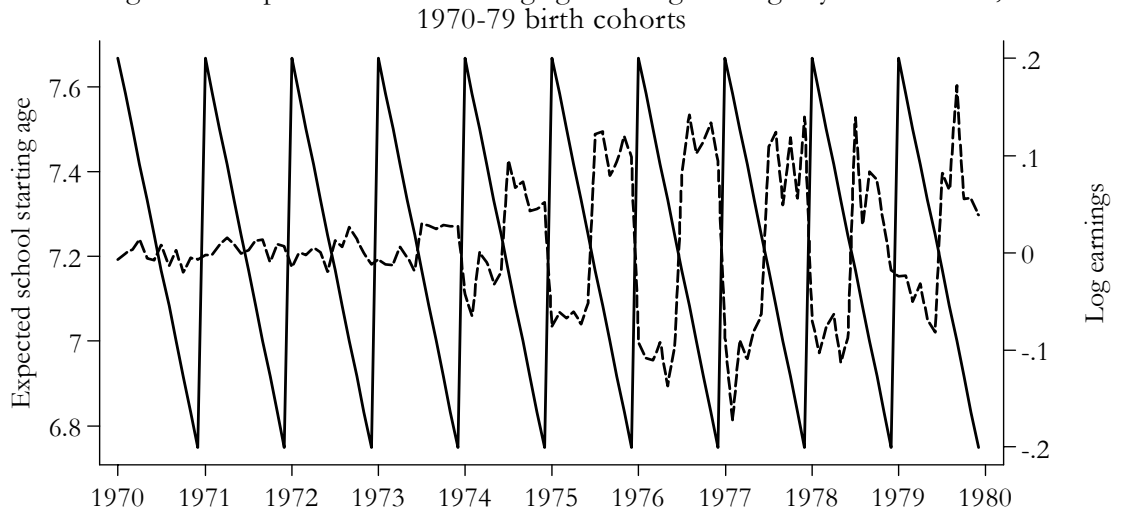

Date of birth

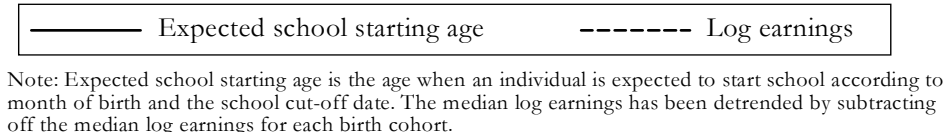

All in all, date of birth and the school cut-off date generate exogenous variation in age at school entry. Actual school starting age by month of birth follows a saw-teeth shaped pattern, with those being born in the beginning of the year being more likely to be older when they start school. The relationship between ninth grade GPA and month of birth follows closely the pattern found 
for the school starting age, suggesting that children who start school when they are somewhat older do better than children who start school when they are younger. Using data on later outcomes, we find that individuals born just before the school cut-of date not only do better in school, they also go on to have more education and somewhat higher earnings. Assuming that parents can not plan births in detail, this can plausibly be attributed to differences in the school starting age.

\section{Empirical considerations}

Figures 4 to 7 suggest a clear link between the variation in age at school entry induced by the school starting age legislations and the performance in school and later in life. However, to be able draw some inference there is need for a more formal analysis. Assume that the outcome (e.g. test scores, grades, years of schooling or earnings) for individual $i$ at time $t$ (the time of data collection) can be written as:

$$
Y_{i t}=\beta_{0}+A_{i t} \beta_{1}+S_{i t}^{C} \beta_{2}+A_{i}^{S} \beta_{3}+\mathbf{X}_{i t} \boldsymbol{\beta}_{4}+\varepsilon_{i t}
$$

where $A_{i t}$ denotes age, $S_{i t}^{C}$ compulsory schooling, $A_{i}^{S}$ the school starting age, $\mathbf{X}_{i t}$ a vector of individual characteristics, and $\varepsilon_{i t}$ an individual specific error component. The school starting age coefficient $\beta_{3}$ is the parameter of primary interest.

There are two main empirical problems with estimating (5) using OLS. First, since parents and school administrators can affect the age when the children start school, age at school entry is endogenous $\left(E\left[A_{i}^{S} \varepsilon_{i t}\right] \neq 0\right)$. Hence, OLS estimates of $\beta_{3}$ might suffer from bias. ${ }^{13}$ Second, for individuals still enrolled in compulsory school, there is an exact linear dependence between age, age at school start and time spent in school $\left(A_{i t}=A_{i}^{S}+S_{i t}^{C}\right)$. It is, thus, not possible to separately identify $\beta_{1}, \beta_{2}$ and $\beta_{3}$ for this population.

The empirical strategy taken in this paper is to exploit the exogenous variation in age at school entry driven by the children's month of birth and the school cut-off date. In particular, children born on each side of the new year, are born at about the same time but differ in their school starting age. This is an application of Thistlethwaite and Cambell's (1960) regression-discontinutiy design, where the regressor of interest (school starting age) can be expressed as

\footnotetext{
${ }^{13}$ In accordance with the Swedish compulsory schooling laws, we assume that individuals cannot affect the length of their compulsory schooling. Hence, we do not treat compulsory schooling as an endogenous variable.
} 
a known discontinuous function of an underlying variable (date of birth). To exploit the exogenous variation induced by the school starting age legislations, we will use the expected school starting age function $\left(f_{i}^{A^{S}}\right)$ as an instrument for actual age at school entry $\left(A_{i}^{S}\right)$. The "first-stage" relation can, thus, be expressed as:

$$
A_{i}^{S}=\pi_{0}+A_{i t} \pi_{1}+S_{i t}^{C} \pi_{2}+f_{i}^{A^{S}} \pi_{3}+\mathbf{X}_{i t} \boldsymbol{\pi}_{4}+\eta_{i t} .
$$

Since $f_{i}^{A^{S}}$ is a deterministic discontinuous function of date of birth, and since age (date of birth) is related both to earnings and educational attainment, it is crucial to account for any direct effect of age on the outcome. Our main approach is to add flexible specifications of date of birth to the model. In particular, we specify birth cohort fixed effects together with a linear month of birth trend to capture (possibly) nonlinear effects of date of birth. Note, however, that adding year-of-birth dummy variables would divide time into calendar years, which is exactly what the school starting age legislation does. To be able to exploit the variation in the school starting age around the new year, we therefore shift the year-of-birth variables six months. Hence, time is divided into one-year-long intervals ranging from July 1st to June 30th the following year (as opposed to January 1st and December 31st the same year). The identifying assumption in this model is, thus, that the shifted year of birth dummies and the linear month of birth trend can remove any direct effect of date of birth on the outcome. For the long-run outcomes (collected at the same point in time), including these controls removes any direct effect of age on the outcomes. As a specification test, we will, however, restrict the sample to individuals born close to the school cut-off date, i.e. those born in December or in January.

All outcome measures are collected at a given amount of compulsory schooling; either in the same grade of compulsory school or when compulsory school is completed. Hence, our data implicitly hold time spent in compulsory school constant and we can drop $S_{i t}^{C}$ from the model. As noted above, the timing of the data collection is crucial for what the estimates reflect. For outcomes collected in the same grade of compulsory school, there is no independent variation in age and age at school start. These estimates may, thus, reflect the combined effect of age and age at school entry. For outcomes collected after compulsory schooling, the exact linear dependence between age, age at school start and compulsory schooling is no longer binding. These estimates will, thus, separately identify the effect of school starting age. 


\section{Regression results}

The purpose of this section is to present a collection of evidence pertaining to the importance of age at school start for schooling and labor market outcomes. We begin in section 6.1 with compulsory school outcomes and in section 6.3 we look at labor market outcomes. Outcomes in school is the natural place to start, although it is then generally not possible to separate the effect of the school starting age from the effect of age differences when the outcome is measured. However, the compulsory school outcomes are interesting, in particular since the descriptive analysis in section 4 showed that there are long-run effects of differences in the school starting age.

In section 6.2 we address a question of great policy significance. Is the school starting age effect due to the fact that it is more productive to start class room training (earlier or) later or is it due to the fact that those starting school at an older age are relatively older within class? If it is primarily a relative age effect, then our estimates may have little to say about the fundamental policy question: Should formal learning start at an earlier or a later age? To address these issues, we make use of the arguably stochastic variation across cohorts within school in the age composition of the individuals' peers. This strategy enables us to obtain a measure of the individuals' relative position in the age distribution. To precede the results, we show in section 6.2 that the relative age of the kids matters but that the effect is minor.

Section 6.3 addresses the long-run effects of differences in the school starting age. We focus on two outcomes: education attainment and earnings. As hinted at earlier, the effects of the school starting age persist into adulthood.

\subsection{Compulsory school outcomes}

In Table 3 we examine the relationship between the school starting age and the grade point average. The grade point average pertains to the ninth grade and we base the estimates on the 1975-83 birth cohorts.

The first column presents the simple OLS estimates. The association between the actual school starting age and student performance is negative. However, this should clearly not be interpreted as the causal effect of the school starting age. Instead, it is driven by the fact that early starters is selected from the pool of well-performing pupils while those with a delayed school start is selected from the pool of under-achievers (see Figure 3). 


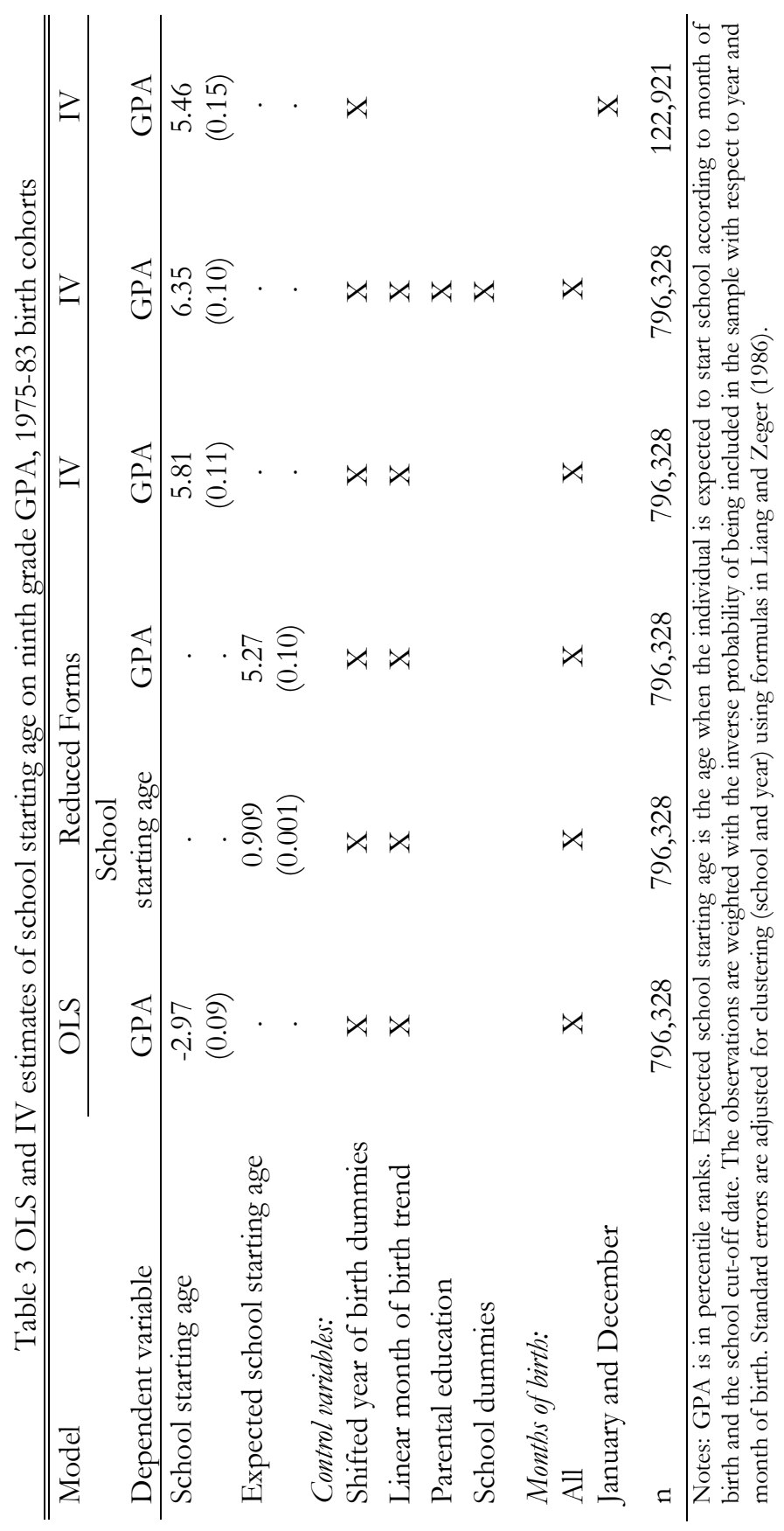


That selection biases the OLS estimate is illustrated by the two reduced form relationships presented in columns 2 and 3. It comes as no surprise that the relationship between the actual school starting age and the expected school starting age is very strong (and positive). Moreover, the relationship between the GPA and the expected school starting age is positive. These two reduced forms imply our preferred IV estimate presented in column 4. Relative to the OLS estimate, the IV approach reverses the relationship between the school starting age and student performance. The causal effect of starting school at an older age is thus positive. The result of increasing the school starting age by a year is that the GPA increases by almost 6 percentile points (which corresponds to 0.2 standard deviations of the transformed GPA distribution).

As illustrated in section 4, our identifying variation comes from the sharp school starting age difference between January and December kids. Whether children are born in December or January would appear to be largely random and therefore, our baseline specification includes a very limited set of controls; the baseline specification only includes a linear age variable and cohort dummies. A priori, we could see little reason for such factors as family background, gender, and school take-up area to bias our estimates. However, if we include such characteristics, the estimate increases by approximately 10 percent as shown by column 5. A closer look at the data, reveals that it is family background that produces the increase in the estimate. Children of highly educated parents tend to be born in December to a greater extent than children of less skilled parents. Despite this finding, we proceed with the limited set of covariates in column 4. The reason is that we have no information on parental education for the older cohorts that we examine in section 6.3. The reader is advised to remember that the estimates are probably biased downwards because we fail to control for family background. ${ }^{1415}$

The sharp discontinuity in the school starting age for children born in December and January also implies that we can control for any smooth function of date of birth and still be able to identify the parameter of interest. We have tried adding higher order polynomials in date of birth, but this does not affect

\footnotetext{
${ }^{14}$ It is reassuring that the bias because of failing to control adequately for family background goes the "right" way. The result we have is that student performance is positively affected by the school starting age. Our baseline estimates are thus biased against this conclusion.

${ }^{15}$ In fact, there is an additional source of downward bias in our estimates. Roughly 2 percent of the cohorts born 1975-83, living in Sweden in 2000, have no grades whatsoever. These individuals are not in our data on grades and, hence, we miss some key information. However, the probability of not being included in the data on grades is decreasing in the school starting age. So, if we think that missing grades data is an indication of poor school achievement, there is a slight downward bias in our estimates.
} 
the estimate and the coefficients on the higher order polynomials are not significant. We have also limited the sample to January and December kids; see column 6 . This has only a minor effect on the estimate. Moreover, the difference between the two estimates is not significant at the $5 \%$ level

Having subjected the baseline specification to a number of specification tests we proceed to Table 4. In Table 4, we report separate estimates by subject, gender, and family background using the baseline specification. Column 1 contains the estimates by subject for the entire sample. Prior to the introduction of the new grading system, students could opt for general and advanced classes in English and Math. The grades from a general and an advanced class are not comparable. Therefore, for the cohorts born 1975-1980, we regress the probability of attending an advanced class for these two subjects. ${ }^{16}$

Overall, the estimates of the key parameter of interest are remarkably stable across subjects. When student performance is measured by grades, the effect of starting a year later hovers around 6 percentile points. The exception from this rule is sports. To some extent this comes as no surprise. Physical development is of course a key ingredient in sports. Sporting activities are also conducted outside the school to a greater extent than for the academic subjects. Therefore, one would think that early advantages tend to persist in sports because sporting activities outside schools tend to be more selective. There is also a substantial literature documenting the importance of season of birth for success in sports; see Musch and Grondin (2001) for a survey.

Turning to the gender differences presented in columns 2 and 3 of Table 4, the school starting age effects do not appear to vary across gender. Again, there is one exception - sports. The starting age is more important for boys. This may be due to the fact that they participate in sporting activities outside the school to a greater extent than girls, and as argued above, the total amount of selection in sports is greater than in any other subject.

Finally, columns 4 and 5 report separate estimates by parental education. Kids having at least one parent with at least three years of upper secondary education are defined as having "Academic parents". As shown by these two columns, this is the point where there is some coefficient heterogeneity. The starting age has a bigger positive effect for those who have parents that are relatively less skilled. The most striking difference across the two groups per-

\footnotetext{
${ }^{16}$ At face value, it is somewhat hard to compare the magnitudes of the estimates across the two defintions of the outcome variables in Table 4. Note, though, that the estimate pertaining to the probability of attending an advanced class in Math corresponds (again) to an effect size of 0.2 standard deviations.
} 
tains the probability of attending advanced classes in Math and English. For instance, in English the effect for kids with relatively less skilled parents is twice the size of the effect for kids with more skilled parents. We think it makes sense to see the greatest differences when it comes to these two outcomes. The choice of attending an advanced class probably reflects family background to a greater extent than grades. Having an initial advantage due to a later school start appears to be more important for outcomes that tend to be more "constrained" by family background.

Table 4 IV estimates of school starting age on ninth grade outcomes, 1975-83 birth cohorts

\begin{tabular}{lccccc}
\hline \hline & All & Females & Males & $\begin{array}{c}\text { Academic } \\
\text { parents }\end{array}$ & $\begin{array}{c}\text { Non-academic } \\
\text { parents }\end{array}$ \\
\hline Grades & & & & & \\
GPA & 5.81 & 5.89 & 5.85 & $5.20^{\mathrm{a}}$ & $5.87^{\mathrm{a}}$ \\
Swedish & $(0.11)$ & $(0.15)$ & $(0.15)$ & $(0.15)$ & $(0.15)$ \\
& 6.11 & $6.52^{\mathrm{b}}$ & $5.97 \mathrm{~b}$ & $5.45^{\mathrm{a}}$ & $6.18^{\mathrm{a}}$ \\
Science & $(0.14)$ & $(0.19)$ & $(0.20)$ & $(0.20)$ & $(0.20)$ \\
& 5.52 & 5.78 & 5.36 & $4.70^{\mathrm{a}}$ & $5.77^{1}$ \\
Social science & $(0.14)$ & $(0.18)$ & $(0.20)$ & $(0.19)$ & $(0.19)$ \\
Sports & 5.98 & $6.43^{\mathrm{a}}$ & $5.68^{\mathrm{a}}$ & $5.17^{\mathrm{a}}$ & $6.17^{\mathrm{a}}$ \\
& $(0.14)$ & $(0.18)$ & $(0.19)$ & $(0.19)$ & $(0.19)$ \\
Advanced class & 9.18 & $6.57 \mathrm{a}$ & $11.65^{\mathrm{a}}$ & 9.14 & 8.90 \\
English & $(0.14)$ & $(0.20)$ & $(0.20)$ & $(0.20)$ & $(0.21)$ \\
& & & & & \\
Mathematics & 0.070 & 0.066 & 0.075 & $0.043^{\mathrm{a}}$ & $0.088^{\mathrm{a}}$ \\
& $(0.003)$ & $(0.004)$ & $(0.005)$ & $(0.004)$ & $(0.005)$ \\
$\mathrm{n}$ & 0.096 & 0.097 & 0.096 & $0.077^{\mathrm{a}}$ & $0.105^{\mathrm{a}}$ \\
& $(0.003)$ & $(0.005)$ & $(0.005)$ & $(0.004)$ & $(0.005)$ \\
& 796,328 & 386,463 & 409,865 & 377,268 & 361,141 \\
\hline
\end{tabular}

Notes: All grades are in percentile ranks. School starting age is instrumented with expected school starting age. All models also include an intercept, shifted year of birth dummy variables and a linear month of birth trend. The observations are weighted with the inverse probability of being included in the sample with respect to year and month of birth. Academic parents means that at least one parent have a long high school degree or higher. The probability of attending an advanced class is estimated using a linear probability model, and restricted to the 1975-80 birth cohorts. Standard errors are adjusted for clustering (school and year) using formulas in Liang and Zeger (1986). a/b/c=the estimates are significantly different from zero at the 1/5/10 per cent level of confidence using a two-sided t-test for females/males and academic/non-academic parents, respectively.

It is difficult to determine whether one should be surprised by the general pattern of the estimates by parental education in Table 4. On the one hand, the pattern is consistent with findings from other educational interventions. For instance, according to the evidence from STAR, class size interventions have greater effects for kids from disadvantaged backgrounds; see Krueger (1999) for example. On the other hand, proponents of early intervention argue that such policies will have particularly beneficial effects for children from disadvantaged 
backgrounds. ${ }^{17}$ However, it is not clear that the argument in favor of early intervention is so pertinent in this context. The alternative to starting school early (in part staying at home with their less skilled parents but also proceeding in child care) may (or may not) be less advantageous for kids from disadvantaged background. But presumably they are not ready for the treatment (formal classroom training) to the same extent as kids from advantaged backgrounds. Some indication that this is what is going on can be obtained by looking at the estimate for sports. Clearly sports does not have a class-room component and, accordingly, we do not find any differences by family background in sports. All in all, then, we think the pattern of the estimates in columns 4 and 5 make sense.

Above we raised some concerns about the informational value of grades. However, these concerns turn out to be unwarranted as shown by Table 5 . In Table 5 we present school starting age effects for the 1948 and 1953 birth cohorts, using the IS data The virtue of these data is that there is information on achievement test scores along with grades for Swedish, English, and Math. The table shows that it does not make much difference whether we measure outcomes in terms of grades or scores on achievement tests. Notice also that there are school starting age effects in the IQ test scores, which is consistent with the view that IQ is "malleable".

As a final sensitivity check we have estimated the effects of the school starting age separately by birth cohort. We do not report these estimates here, since it turns out that the effects vary across birth cohorts only to a limited extent.

\subsection{Is it a relative age effect?}

The question that we are framing this paper with (Is it more productive to start school earlier?) is a question about the effect of the absolute school starting age. But the effects may also be due to the relative age of kids, since, e.g., those born in December are also the youngest in the class. The estimates on the school starting age in, e.g., Table 4 capture both of these effects.

But for policy purposes one would most often like to free the estimates of relative age effects. A key policy question is what would happen to school performance if the school start is pushed forward by, say, one year for all children.

\footnotetext{
${ }^{17}$ Some qualifications are probably due here. Proponents of early intervention presumably have other treatments in mind when presenting their case. Early childhood programs may involve learning social skills and behavior to a greater extent than formal class room training. Moreover, while the family background characteristic we consider is a sensible measure of family skills, it is not a direct indicator of troubled families.
} 
Clearly, such a policy change will not change the relative age distribution of kids.

Table 5 IV estimates of school starting age on different outcomes in $6^{\text {th }}$ grade, 1948 and 1953 birth cohorts

\begin{tabular}{|c|c|c|}
\hline & $\begin{array}{c}1948 \\
\text { birth cohort }\end{array}$ & $\begin{array}{c}1953 \\
\text { birth cohort }\end{array}$ \\
\hline \multicolumn{3}{|l|}{ IQ-test scores: } \\
\hline Verbal & $\begin{array}{c}8.37 \\
(1.05)\end{array}$ & $\begin{array}{c}8.30 \\
(1.22)\end{array}$ \\
\hline Spatial & $\begin{array}{l}6.96 \\
(1.06)\end{array}$ & $\begin{array}{c}4.59 \\
(1.22)\end{array}$ \\
\hline Number series & $\begin{array}{c}4.84 \\
(1.05)\end{array}$ & $\begin{array}{c}5.51 \\
(1.21)\end{array}$ \\
\hline \multicolumn{3}{|c|}{ Achievement test scores: } \\
\hline Swedish & $\begin{array}{c}6.52 \\
(1.00)\end{array}$ & $\begin{array}{c}8.23 \\
(1.21)\end{array}$ \\
\hline English & $\begin{array}{c}4.33 \\
(1.04)\end{array}$ & $\begin{array}{c}5.95 \\
(1.21)\end{array}$ \\
\hline Mathematics & $\begin{array}{c}6.42 \\
(1.03)\end{array}$ & $\begin{array}{c}8.02 \\
(1.21)\end{array}$ \\
\hline \multicolumn{3}{|l|}{ Grades: } \\
\hline Swedish & $\begin{array}{c}6.15 \\
(0.99)\end{array}$ & $\begin{array}{c}6.96 \\
(1.16)\end{array}$ \\
\hline English & $\begin{array}{c}4.31 \\
(1.00)\end{array}$ & $\begin{array}{c}5.77 \\
(1.17)\end{array}$ \\
\hline Mathematics & $\begin{array}{c}7.01 \\
(1.02)\end{array}$ & $\begin{array}{c}8.15 \\
(1.17)\end{array}$ \\
\hline $\mathrm{n}$ & 11,950 & 9,927 \\
\hline
\end{tabular}

To estimate the relative age effect we exploit the within school variation in the age composition across cohorts. ${ }^{18}$ The individuals' position in the age distribution is simply the percentile rank in the age distribution in the school. We

\footnotetext{
${ }^{18}$ Here, the school refers to the school in ninth grade. This might yield a bias in the unlikely event that across school mobility is driven by variations in the age distribution across schools. Ideally we would have liked to rank the individuals within class and then used the within school variation in the expected school starting age distribution as an instrument. However, the class information is unavailable to us. Notice, that this preferred strategy would have no effect on the precision of the estimates but may affect the relative size of the estimates. We have also performed some sensitivity checks restricting the analysis to pupils from small schools. The idea is that that the within school variation will be a better representation of the within class variation in small schools. As it turned out, the relative age effect were never significant in the sample restricted to small schools.
} 
instrument that with the percentile rank according to the individuals' expected school starting age within the expected school starting age distribution. Thus, this strategy implies that we are instrumenting the actual school starting age as well as the actual relative ranking within school. We choose units such that the percentile rank is defined on the unit interval. This implies that there will be roughly a full year difference between the top ranked individual (assigned a rank of 1 and born in January) and the lowest ranked individual (assigned a rank of 0 and born in December). The magnitudes of the estimates on the absolute age effect and the relative age effect should thus be approximately comparable.

Table 6 presents the estimates. The general outline is identical to Table 4, i.e., we present separate estimates by subject, gender and family background. Each cell, however, presents two sets of estimates. The top one is the absolute age effect while the bottom one in italics is the relative age effect. The overall message conveyed by these results is that the absolute age effect is much more important than the relative age effect. It is relevant to ask whether this is due to the relative age effect being poorly identified. However, this is not case. The standard errors of the relative age effects are small. Indeed, the relative age effects are always significantly smaller than the absolute ones. That the identification strategy makes sense is also illustrated by the row for sports. When it comes to sports the relative age effect is significant and accounts for roughly a quarter of the total effect. The importance of the relative age is well documented in the literature, particularly for team sports; see Musch and Grondin (2001).

\subsection{Educational attainment and earnings}

Let us turn to the longer term effects of variations in the school starting age. In this case, the age when measuring outcomes and the school starting age varies independently when comparing January and December kids; see Figure 4. Therefore, these estimates can be thought of as giving the pure (long-run) effect of variations in the school starting age. 
Table 6 IV estimates of absolute and relative school starting age on ninth grade outcomes, 1975-83 birth cohorts

\begin{tabular}{|c|c|c|c|c|c|}
\hline & All & Females & Males & $\begin{array}{l}\text { Academic } \\
\text { parents }\end{array}$ & $\begin{array}{l}\text { Non-academic } \\
\text { parents }\end{array}$ \\
\hline \multicolumn{6}{|l|}{ Grades } \\
\hline \multirow[t]{4}{*}{ GPA } & 5.41 & 5.44 & 6.05 & 4.30 & 5.49 \\
\hline & $(0.62)$ & $(0.91)$ & $(0.88)$ & $(0.87)$ & $(0.84)$ \\
\hline & 0.38 & 0.41 & -0.22 & 0.92 & 0.35 \\
\hline & $(0.63)$ & $(0.92)$ & $(0.89)$ & $(0.88)$ & $(0.85)$ \\
\hline \multirow[t]{4}{*}{ Swedish } & 6.07 & 5.54 & 7.71 & 4.95 & 5.77 \\
\hline & $(0.85)$ & $(1.20)$ & $(1.15)$ & $(1.21)$ & (1.14) \\
\hline & 0.00 & 0.92 & -1.82 & 0.48 & 0.37 \\
\hline & $(0.86)$ & (1.21) & $(1.16)$ & $(1.22)$ & (1.16) \\
\hline \multirow[t]{4}{*}{ Science } & 4.36 & 4.32 & 5.01 & 2.73 & 4.78 \\
\hline & $(0.79)$ & $(1.15)$ & $(1.15)$ & $(1.10)$ & $(1.07)$ \\
\hline & 1.18 & 1.45 & 0.36 & 2.00 & 1.00 \\
\hline & $(0.80)$ & (1.16) & $(1.16)$ & (1.11) & $(1.08)$ \\
\hline \multirow[t]{4}{*}{ Social science } & 5.83 & 6.09 & 6.26 & 5.08 & 6.04 \\
\hline & $(0.81)$ & $(1.16)$ & $(1.14)$ & (1.11) & (1.08) \\
\hline & 0.11 & 0.27 & -0.62 & 0.06 & 0.08 \\
\hline & $(0.81)$ & (1.17) & $(1.15)$ & (1.12) & (1.09) \\
\hline \multirow[t]{4}{*}{ Sports } & 6.80 & $4.94^{b}$ & $8.75^{b}$ & 5.53 & 7.17 \\
\hline & $(0.91)$ & (1.21) & (1.23) & $(1.22)$ & $(1.25)$ \\
\hline & 2.48 & 1.70 & 3.00 & 3.79 & 1.81 \\
\hline & $(0.92)$ & (1.23) & (1.24) & (1.23) & $(1.27)$ \\
\hline \multicolumn{6}{|l|}{ Advanced class } \\
\hline \multirow[t]{4}{*}{ English } & 0.047 & 0.039 & 0.061 & $0.004^{a}$ & $0.080^{a}$ \\
\hline & $(0.025)$ & $(0.030)$ & $(0.031)$ & $(0.029)$ & $(0.030)$ \\
\hline & 0.023 & 0.026 & 0.014 & 0.039 & 0.010 \\
\hline & $(0.025)$ & $(0.030)$ & $(0.031)$ & $(0.030)$ & $(0.031)$ \\
\hline \multirow[t]{4}{*}{ Mathematics } & 0.100 & 0.101 & 0.104 & 0.084 & 0.101 \\
\hline & $(0.023)$ & $(0.030)$ & $(0.029)$ & $(0.027)$ & $(0.029)$ \\
\hline & -0.005 & -0.006 & -0.008 & -0.008 & 0.004 \\
\hline & $(0.023)$ & $(0.030)$ & $(0.029)$ & $(0.028)$ & $(0.029)$ \\
\hline $\mathrm{n}$ & 796,328 & 386,463 & 409,865 & 377,268 & 361,141 \\
\hline
\end{tabular}

Notes: All grades are in percentile ranks. The effect of (absolute) age at school start is in normal fonts; the effect of relative age in class is in italics. School starting age is instrumented with expected school starting age. Relative school starting age is the percentile rank (divided by 100) of the individual's school starting age in the school and year, and is instrumented with the expected school starting age percentile rank. All models also include an intercept, shifted year of birth dummy variables, a linear month of birth trend and school fixed effects. The observations are weighted with the inverse probability of being included in the sample with respect to year and month of birth. Academic parents means that at least one parent have a long high school degree or higher. The probability of attending an advanced class is estimated using a linear probability model, and restricted to the 1975-80 birth cohorts. Robust standard errors are in parentheses. a/b/c=the estimates are significantly different from zero at the $1 / 5 / 10$ per cent level of confidence using a two-sided t-test for females/males and academic/non-academic parents, respectively. 
Table 7 IV estimates of school starting age on various educational outcomes

\begin{tabular}{|c|c|c|c|c|c|}
\hline & All & Females & Males & $\begin{array}{l}\text { Academic } \\
\text { parents }\end{array}$ & $\begin{array}{c}\text { Non-academic } \\
\text { parents }\end{array}$ \\
\hline & \multicolumn{5}{|c|}{ 1940-49 Birth cohorts } \\
\hline \multirow[t]{2}{*}{ Schooling } & 0.2722 & 0.2738 & 0.2704 & . & . \\
\hline & $(0.0146)$ & $(0.0202)$ & $(0.0209)$ & . & . \\
\hline \multirow[t]{2}{*}{$\mathrm{P}($ College $)$} & 0.0326 & 0.0355 & 0.0298 & . & . \\
\hline & $(0.0021)$ & $(0.0030)$ & $(0.0029)$ & . & . \\
\hline \multirow[t]{2}{*}{$\mathrm{n}$} & $1,029,797$ & 508,005 & 521,792 & & \\
\hline & \multicolumn{5}{|c|}{ 1950-59 Birth cohorts } \\
\hline \multirow[t]{2}{*}{ Schooling } & 0.1254 & $0.1558^{b}$ & $0.0963^{\mathrm{b}}$ & . & . \\
\hline & $(0.0129)$ & $(0.0180)$ & $(0.0184)$ & . & . \\
\hline \multirow[t]{2}{*}{$\mathrm{P}($ College $)$} & 0.0204 & $0.0248^{c}$ & $0.0163^{c}$ & . & . \\
\hline & $(0.0023)$ & $(0.0034)$ & $(0.0031)$ & . & . \\
\hline \multirow[t]{2}{*}{$\mathrm{n}$} & 965,514 & 472,370 & 493,144 & & \\
\hline & \multicolumn{5}{|c|}{ 1960-69 Birth cohorts } \\
\hline \multirow[t]{2}{*}{ Schooling } & 0.1296 & 0.1281 & 0.1314 & 0.1231 & 0.1111 \\
\hline & $(0.0109)$ & $(0.0154)$ & $(0.0154)$ & $(0.0199)$ & $(0.0123)$ \\
\hline \multirow[t]{2}{*}{$\mathrm{P}($ College $)$} & 0.0243 & $0.0198^{\mathrm{b}}$ & $0.0286^{\mathrm{b}}$ & 0.0258 & 0.0198 \\
\hline & $(0.0022)$ & $(0.0032)$ & $(0.0030)$ & $(0.0040)$ & $(0.0025)$ \\
\hline \multirow[t]{2}{*}{$\mathrm{n}$} & $1,021,780$ & 496,919 & 524,861 & 334,851 & 619,301 \\
\hline & \multicolumn{5}{|c|}{ 1970-79 Birth cohorts } \\
\hline \multirow[t]{2}{*}{ Schooling } & -0.0143 & $-0.0330^{\mathrm{b}}$ & $0.0085^{\mathrm{b}}$ & $-0.0969^{a}$ & $0.0314^{\mathrm{a}}$ \\
\hline & $(0.0101)$ & $(0.0145)$ & $(0.0140)$ & $(0.0143)$ & $(0.0131)$ \\
\hline \multirow[t]{2}{*}{$\mathrm{P}($ College $)$} & -0.0077 & -0.0095 & -0.0051 & $-0.0268^{a}$ & $0.0030^{\mathrm{a}}$ \\
\hline & $(0.0022)$ & $(0.0032)$ & $(0.0030)$ & $(0.0033)$ & $(0.0026)$ \\
\hline \multirow[t]{2}{*}{$\mathrm{n}$} & 954,477 & 461,668 & 492,809 & 454,348 & 484,618 \\
\hline & \multicolumn{5}{|c|}{ All birth cohorts (1935-84) } \\
\hline \multirow[t]{2}{*}{ Schooling } & 0.0620 & 0.0575 & 0.0672 & . & . \\
\hline & $(0.0055)$ & $(0.0077)$ & $(0.0079)$ & & . \\
\hline \multirow[t]{2}{*}{$\mathrm{P}($ College $)$} & 0.0138 & 0.0133 & 0.0145 & . & . \\
\hline & $(0.0009)$ & $(0.0014)$ & $(0.0013)$ & . & . \\
\hline $\mathrm{n}$ & $4,778,333$ & $2,337,313$ & $2,441,020$ & & \\
\hline
\end{tabular}

Notes: School starting age is instrumented with expected school starting age. All models also include an intercept, shifted year of birth dummy variables and a linear month of birth trend. Academic parents means that at least one parent have a long high school degree or higher. The observations are weighted with the inverse probability of being included in the sample with respect to year and month of birth. Only individuals born after 1960 have sufficiently high share of non-missing information on parental education to be used in the analysis. The probability of having attended college is estimated using a linear probability model. Robust standard errors are in parenthesis. $a / b / c=$ the estimates are significantly different from zero at the $1 / 5 / 10$ per cent level of confidence using a two-sided t-test for females $/ \mathrm{males}$ and academic/non-academic parents, respectively.

Table 7 starts by looking at educational attainment. The educational outcomes are represented by (imputed) years of schooling and the probability of attending college. The probability of attending college is, in turn, defined as having a degree from university education which is at least two years long. From 
top to bottom we present separate estimates for individuals born in the 1940s, 1950s, and so on. The bottom panel contains results for all birth cohorts - born 1935-84 - pooled together.

The school starting age effects for all cohorts are consistent with the estimates presented in section 6.1. Except for the cohorts born in the 1970s all individuals benefit from starting school at an older age. The reason for the negative effect for those born in the 1970s is that a substantial portion of these individuals have not yet finished their schooling careers. For the remaining cohorts, the effect of starting school one year later varies from 0.13 years of schooling (1950s and 1960s) to 0.27 years of schooling (1940s). The effect for those born in the 1940s is thus substantially bigger than the effect for those born in the 1950s or the 1960s. To a limited extent, this is driven by the evolution of the standard deviation of the schooling distribution (see Figure 1). But even if we convert the effects into standard deviation units - 0.09 SD (1940s) and 0.05 SD (1950s and 1960s) - the difference across cohorts remains. This difference is interesting and therefore we probe deeper into this issue.

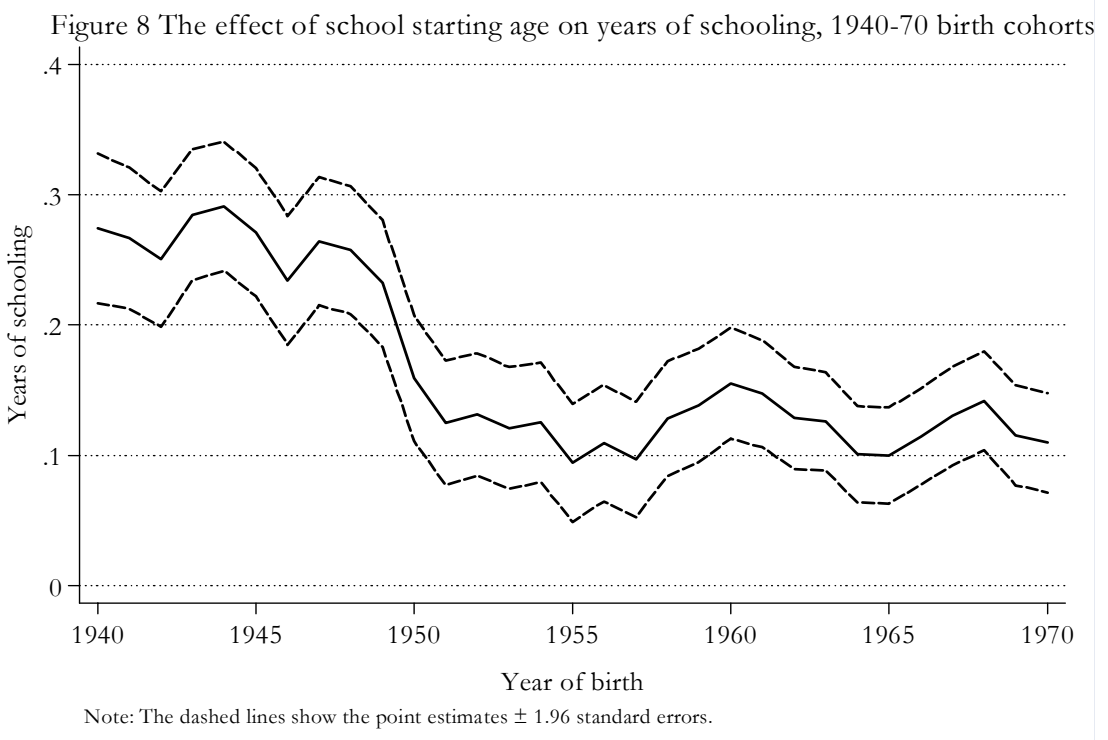

In Figure 8 we report separate estimates by birth cohort. There is a large downward jump in the effect of the school starting age on education attainment occurring around 1950. A somewhat speculative interpretation is that this downward jump has to do with the more selective nature of the schooling system prior to the introduction of the compulsory school. Although the implementation of the compulsory school was gradual it seems to have been 
introduced rather rapidly: a third of students born in 1948 went to school according to the new compulsory school system; among students born in 1953 the share attending a compulsory school had increased to $80 \%$.

The school starting age effect seems to be smaller when it comes to the longrun schooling outcomes considered here (0.05 SD for those born in the 1960s) in comparison with the compulsory school outcomes considered in section 6.1 (0.2 $\mathrm{SD})$. That the long-run effects are smaller seems sensible given depreciation. Moreover, achievement gains are presumably not translated fully into increases in years of schooling. But it also seems likely that it reflects the fact that we cannot distinguish between the school starting age and the age effect for the compulsory school outcomes.

Table 7 also shows that the parameter of interest varies somewhat by gender, but there is no consistent pattern across cohorts. The coefficient of interest does not vary by family background, as evidenced by the estimates for the 1960s cohorts. Thus, unlike the compulsory school outcomes, the school starting age effects do not seem to vary by groups for these long-run schooling outcomes.

Table 8 reports the estimated school starting age effects for earnings. The table has an identical outline as the previous one. The estimates by birth cohort have a similar flavor as the estimates for educational attainment. There is a positive earnings effect of starting school at an older age and this effect is largest for those born in the 1940s. For the cohorts born in the 1950s and 1960s, however, the effects are no longer significant. Notice that the earnings estimates reflect to opposing forces. On the one hand, starting school later will raise educational attainment. On the other hand, starting school later implies forgone labor market experience; the forgone experience effect operates both directly - individuals that start school later also enter the labor market later - and indirectly - those who start later have more schooling and hence less experience. This forgone experience effect should be most important for the youngest cohorts when the experience profile is most steep.

The bottom panel presents earnings estimates for all individuals in our sample. This estimate is interesting since it can be interpreted as the individual net earnings effect over the life-cycle of starting school a year later ${ }^{19}$.As can be seen, this overall effect appears to be negative. The opportunity cost of having kids start school later outweighs the earnings gain accruing later on in life. Appropriate discounting of the gains and losses would only strengthen this conclusion.

\footnotetext{
${ }^{19}$ This is of course based on the assumption that the cross-section estimate is a fair approximation of individual life-cycle earnings.
} 
Table 8 IV estimates of school starting age on earnings in 2000

\begin{tabular}{|c|c|c|c|c|c|}
\hline & All & Females & Males & $\begin{array}{l}\text { Academic } \\
\text { parents }\end{array}$ & $\begin{array}{c}\text { Non-academic } \\
\text { parents }\end{array}$ \\
\hline & \multicolumn{5}{|c|}{ 1940-49 Birth cohorts } \\
\hline \multirow[t]{2}{*}{ Earnings } & 3150 & 3331 & 3198 & . & . \\
\hline & $(797)$ & $(778)$ & $(1342)$ & . & \\
\hline \multirow{2}{*}{$\log ($ Earnings $)$} & 0.0054 & 0.0081 & 0.0042 & . & . \\
\hline & $(0.0023)$ & $(0.0027)$ & $(0.0033)$ & . & . \\
\hline \multirow[t]{2}{*}{$\mathrm{n}$} & $1,029,797$ & 508,005 & 521,792 & . & . \\
\hline & \multicolumn{5}{|c|}{ 1950-59 Birth cohorts } \\
\hline \multirow[t]{2}{*}{ Earnings } & 611 & 471 & 737 & . & . \\
\hline & $(844)$ & $(797)$ & $(1426)$ & . & . \\
\hline \multirow{2}{*}{$\log ($ Earnings $)$} & 0.0009 & -0.0003 & 0.0012 & . & . \\
\hline & $(0.0022)$ & $(0.0027)$ & $(0.0031)$ & . & . \\
\hline \multirow[t]{2}{*}{$\mathrm{n}$} & 965,514 & 472,370 & 493,144 & . & . \\
\hline & \multicolumn{5}{|c|}{ 1960-69 Birth cohorts } \\
\hline \multirow[t]{2}{*}{ Earnings } & 396 & 113 & 584 & $2536^{\mathrm{b}}$ & $-1081^{b}$ \\
\hline & $(740)$ & $(724)$ & $(1204)$ & $(1572)$ & (784) \\
\hline \multirow[t]{2}{*}{ Log(Earnings) } & 0.0029 & 0.0021 & 0.0018 & 0.0047 & -0.0011 \\
\hline & $(0.0021)$ & $(0.0028)$ & $(0.0027)$ & $(0.0040)$ & $(0.0025)$ \\
\hline \multirow[t]{2}{*}{ n } & $1,021,780$ & 496,919 & 524,861 & 334,851 & 619,301 \\
\hline & \multicolumn{5}{|c|}{ 1970-79 Birth cohorts } \\
\hline Earnings & $\begin{array}{r}-7319 \\
(465)\end{array}$ & $\begin{array}{r}-5782^{a} \\
(561)\end{array}$ & $\begin{array}{r}-9363^{a} \\
(699)\end{array}$ & $\begin{array}{r}-10464^{a} \\
(696)\end{array}$ & $\begin{array}{r}-4097 a \\
(621)\end{array}$ \\
\hline \multirow[t]{2}{*}{ Log(Earnings) } & -0.0278 & $-0.0208^{a}$ & -0.0359 a & $-0.0357 \mathrm{a}$ & $-0.0211^{a}$ \\
\hline & $(0.0019)$ & $(0.0027)$ & $(0.0025)$ & $(0.0030)$ & $(0.0025)$ \\
\hline \multirow[t]{2}{*}{$\mathrm{n}$} & 954,477 & 461,668 & 492,809 & 454,348 & 484,618 \\
\hline & \multicolumn{5}{|c|}{ All birth cohorts (1935-84) } \\
\hline \multirow[t]{2}{*}{ Earnings } & -1350 & -952 & -1828 & . & . \\
\hline & (312) & (307) & (521) & . & \\
\hline \multirow[t]{2}{*}{ Log(Earnings) } & -0.0064 & $-0.0173^{c}$ & $-0.0014^{c}$ & . & . \\
\hline & $(0.0048)$ & $(0.0051)$ & $(0.0066)$ & . & \\
\hline n & $4,778,333$ & $2,337,313$ & $2,441,020$ & . & . \\
\hline \multicolumn{6}{|c|}{$\begin{array}{l}\text { Notes: School starting age is instrumented with expected school starting age. All models also include an } \\
\text { intercept, shifted year of birth dummy variables and a linear month of birth trend. Academic parents } \\
\text { means that at least one parent have a long high school degree or better. The observations are weighted } \\
\text { with the inverse probability of being included in the sample with respect to year and month of birth. Only } \\
\text { individuals born after } 1960 \text { have sufficiently high share of non-missing information on parental education } \\
\text { to be used in the analysis. The log earnings are restricted to individuals earning more than } 100,000 \text { SEK, } \\
\text { which reduces the samples with roughly } 30 \text { per cent. Robust standard errors are in parenthesis. a } / \mathrm{b} / \mathrm{c}=\text { the } \\
\text { estimates are significantly different from zero at the } 1 / 5 / 10 \text { per cent level of confidence using a two-sided } \\
\text { t-test for females/males and academic/non-academic parents, respectively. }\end{array}$} \\
\hline
\end{tabular}




\section{Concluding remarks}

In this paper we have presented a collection of evidence suggesting that starting school at an older age is beneficial for scholastic achievement. Starting school one year later increases compulsory school performance by roughly 0.2 standard deviations (SD). Moreover, the effects persist into adulthood. Late school starters go on to have more schooling and they have a slight long-run earnings advantage in comparison to early starters. The effect sizes are much smaller for earnings (0-0.02 SD) than for educational attainment (0.05-0.09 SD).

Our evidence also suggests that the effects we measure are due to absolute maturity rather than to the relative age in the class. Taken at face value, this implies that pushing the start of classroom training, e.g., one year earlier will be detrimental for children, at least for their scholastic achievement.

Although school performance seems to improved by the school starting age, having kids start school one year later clearly entails an opportunity cost. Late school starters have less labor market experience and fewer years on the labor market (given the retirement age). Indeed, taken seriously, our estimates suggest that starting school one year later implies a negative (but small) net earnings return over the life cycle.

Thus, there appears to be a trade-off: if one is concerned with the scholastic achivement of children, our estimates suggest a slightly higher school starting age; while if one is concerned with their life-time earnings the conclusion appears to be the opposite. Are there any ways to mitigate this apparent trade-off? To reduce the detrimental effects on school performance of an early school start, some adaption of pedagogical techniques is presumably required. As argued by Stipek (2002): The appropriate question is not whether kids are ready for school - it is whether schools are ready for children. Older kids appear to be better prepared for classroom training. Younger kids may well be more receptive to other forms of learning. 


\section{References}

Angrist, J and A Krueger (1991), Does Compulsory School Attendance Affect Schooling and Earnings? Quarterly Journal of Economics, 106, 979-1014.

Angrist, J and A Krueger (1992), The Effect of Age at School Entry on Educational Attainment: An Application of Instrumental Variables with Moments from Two Samples, Journal of American Statistical Association, 87, 328-336

Barnett, S (1992), Benefits of Compensatory Preschool Education, Journal of Human Resources, 27, 279-311.

Bedard, K and E Dhuey (2005), The Persistence of Early Childhood Maturity: International Evidence of Long-Run Age Effects, mimeo, Department of Economics, University of California, Santa Barbara.

Bound, J, D Jaeger, and R Baker (1995), Problems with Instrumental Variables Estimation when the Correlation between the Instrument and the Endogenous Explanatory Variable is Weak, Journal of American Statistical Association, 90, 443-50.

Byrd, R, M Weitzman, and P Auinger (1997), Increased Behavior Problems Associated with Delayed School Entry and Delayed School Progress, $\mathrm{Pe}$ diatrics, 100, 664-61.

Cahan, S and N Cohen (1989), Age Versus Schooling Effects on Intelligence Development, Child Development, 60, 1239-49.

Cahan, S and D Davis (1987), A Between-Grade-Levels Approach to the Investigation of the Absolute Effects of Schooling on Achievement, American Educational Research Journal, 24, 1-13.

Carneiro, P and J Heckman (2003), Human Capital Policy, in B. Friedman (ed), Inequality in America: What Role for Human Capital Policies, MIT Press, Cambridge.

Casio, E and E Lewis (2004), Schooling and the AFQT: Evidence from School Entry Laws, University of California, Davis Working Paper.

Corman, H (2003) The Effects of State Policies, Individual Characteristics, Family Characteristics, and Neighbourhood Characteristics on Grade Repetition in the United States, Economics of Education Review, 22, 409-20.

Graue, E and J DiPerna (2000), Redshirting and Early Retention: Who Gets the "Gift of Time" and What are its Outcomes?, American Education Review Journal, 37, 509-34.

Currie, J (2001), Early Childhood Education Programs, Journal of Economic Perspectives, 15, 213-38.

Datar, A (2005), Does Delaying Kindergarten Entrance Give Children a Head 
Start?, Economics of Education Review, forthcoming.

Del Mondo, E and F Galindo-Rueda (2004), Do a Few Months of Compulsory Schooling Matter? The Education and Labour Market Impact of School Leaving Rules, IZA Discussion Paper 1233.

Eide, E and M Sholwater (2001), The Effect of Grade Retention on Educational and Labor Market Outcomes, Economics of Education Review, 20, 563576.

Fertig, M and J Kluve (2005), The Effect of Age at School Entry on Educational Attainment in Germany, IZA Discussion Paper 1507.

Gunnarsson, L, B Martin Korpi and U Nordenstam (1999), Early Childhood Education and Care Policy in Sweden: Background report prepared for the OECD Thematic Review, Ministry of Education and Science.

Hansen, K, J Heckman and K Mullen (2004), The Effect of Schooling and Ability on Achievement Test Scores, Journal of Econometrics, 121, 39-98.

Jones, M and K Mandeville (1990), The Effect of Age at School Entry on Reading Achievement Scores among South Carolina Students, Remedial and Special Education, 11, 56-62.

Krueger, A (1999), Experimental Estimates of Education Production Functions, Quarterly Journal of Economics, 114, 497-532.

Langer, P, J Kalk, and D Searls (1984), Age of Admission and Trends in Achievement: A Comparison of Blacks and Caucasians, American Educational Research Journal, 21, 61-78.

Leuven, E, M Lindahl, H Oosterbeek, and D Webbink (2004), New Evidence on the Effect of Time in School on Early Achievement, manuscript, SOFI, University of Stockholm.

Liang, K-Y and S Zeger (1986), Longitudinal Data Analysis Using Linearized General Models, Biometrika, 73, 13-22.

May, D, D Kundert, and D Brent (1995), Does Delayed School Entry Reduce Later Grade Retentions and Use of Special Education Services?, Remedial and Special Education, 16, 288-94.

Mayer, S and D Knutson (1999), Does the Timing of School Affect How Much Children Learn?, in S Mayer and P Peterson (eds), Earning and Learning: How Schools Matter, Brookings Institution Press, Washington DC.

Morrison, F, E Griffith, and D Alberts (1997), Nature-Nurture in the Classroom: Entrance Age, School Readiness and Learning in Children, Developmental Psychology, 33, 254-62.

Musch, J and S Grondin (2001), Unequal Competition as an Impediment to Personal Development: A Review of the Relative Age Effect in Sport, 
Developmental Review, 21, 147-67.

OECD (2003), Education at a Glance, Organization for Economic Cooperation and Development, Paris.

Plug, E (2001), Season of Birth, Schooling and Earnings, Journal of Economic Psychology, 22, 641-60.

Shonkoff, J and D Phillips, eds (2000), From Neurons to Neighborhoods: The Science of Early Childhood Development, National Academy Press, Washington DC.

Stipek, D (2002), At What Age Should Children Enter Kindergarten? A Question for Policy Makers and Parents, Social Policy Report, 16, 3-16.

Strøm, B (2003), Student Achievement and Birthday Effects, mimeo, Department of Economics, Norwegian University of Science and Technology.

Thistlethwaite, D, and D Campbell (1960), Regression-Discontinuity Analysis: An Alternative to the Ex Post Facto Experiment, Journal of Educational Psychology, 51, 309-17 


\section{Appendix}

Table A1 Descriptive statistics, 1935-84 birth cohorts

\begin{tabular}{lrrrr}
\hline \multicolumn{1}{c}{ Variable } & Mean & S.D. & \multicolumn{1}{c}{ Min } & Max \\
\hline Age in 2000 & 40.70 & 13.91 & 16.00 & 65.92 \\
Woman & 0.49 & 0.50 & 0.00 & 1.00 \\
Mother's years of education & 9.46 & 2.35 & 6.60 & 22.00 \\
Father's years of education & 9.51 & 2.43 & 6.60 & 22.00 \\
School starting age & 7.21 & 0.26 & 4.96 & 10.30 \\
Expected school starting age & 7.22 & 0.28 & 6.75 & 7.67 \\
Years of schooling in 2000 & 12.11 & 2.76 & 3.00 & 20.40 \\
P(College in 2000) & 0.27 & 0.45 & 0.00 & 1.00 \\
Earnings in 2000 & 157,918 & 159,420 & 0 & $28,928,800$ \\
Log(Earnings in 2000) & 12.32 & 0.39 & 11.51 & 17.18
\end{tabular}

Notes: Expected school starting age is the age when the individual is expected to start school according to month of birth and the school cut-off date. The log earnings in 2000 is restricted to individuals earning more than SEK 100,000. For all other variables the number of observations is 4,778,333. 